University of Nebraska - Lincoln

DigitalCommons@University of Nebraska - Lincoln

USDA Wildlife Services - Staff Publications

U.S. Department of Agriculture: Animal and Plant Health Inspection Service

$1-27-2020$

\title{
Optimal bait density for delivery of acute toxicants to vertebrate pests
}

Kim M. Pepin

USA National Wildlife Research Center, USDA-APHIS, kim.m.pepin@aphis.usda.gov

Nathan P. Snow

USA National Wildlife Research Center, USDA-APHIS

Kurt C. VerCauteren

USA National Wildlife Research Center, USDA-APHIS, kurt.c.vercauteren@usda.gov

Follow this and additional works at: https://digitalcommons.unl.edu/icwdm_usdanwrc

Part of the Natural Resources and Conservation Commons, Natural Resources Management and Policy Commons, Other Environmental Sciences Commons, Other Veterinary Medicine Commons, Population Biology Commons, Terrestrial and Aquatic Ecology Commons, Veterinary Infectious Diseases Commons, Veterinary Microbiology and Immunobiology Commons, Veterinary Preventive Medicine, Epidemiology, and Public Health Commons, and the Zoology Commons

Pepin, Kim M.; Snow, Nathan P.; and VerCauteren, Kurt C., "Optimal bait density for delivery of acute toxicants to vertebrate pests" (2020). USDA Wildlife Services - Staff Publications. 2310.

https://digitalcommons.unl.edu/icwdm_usdanwrc/2310

This Article is brought to you for free and open access by the U.S. Department of Agriculture: Animal and Plant Health Inspection Service at DigitalCommons@University of Nebraska - Lincoln. It has been accepted for inclusion in USDA Wildlife Services - Staff Publications by an authorized administrator of DigitalCommons@University of Nebraska - Lincoln. 


\title{
Optimal bait density for delivery of acute toxicants to vertebrate pests
}

\author{
Kim M. Pepin ${ }^{1} \mathbb{D} \cdot$ Nathan P. Snow ${ }^{1} \cdot$ Kurt C. VerCauteren ${ }^{1}$ \\ Received: 7 February 2019 / Accepted: 16 January 2020 / Published online: 27 January 2020 \\ (c) This is a U.S. Government work and not under copyright protection in the US; foreign copyright protection may apply. 2020
}

\begin{abstract}
Oral baiting is a fundamental method for delivering toxicants to pest species. Planning baiting strategies is challenging because bait-consumption rates depend on dynamic processes including space use and demographics of the target species. To determine cost-effective strategies for optimizing baiting, we developed a spatially explicit model of population dynamics using field-based measures of wild-pig (Sus scrofa) space use, bait consumption, and mortality probabilities. The most costeffective baiting strategy depended strongly on the population reduction objective and initial density. A wide range of baiting strategies were cost-effective when the objective was $80 \%$ population reduction. In contrast, only a narrow range of baiting strategies allowed for a $99 \%$ reduction. Cost-effectiveness was lower for low densities of wild pigs because of the increased effort for locating target animals. Bait avoidance due to aversive conditioning from sub-lethal dosing had only minor effects on cost-effectiveness when the objective was an $80 \%$ reduction, whereas the effect was much stronger when the objective was 99\% population reduction. Our results showed that a bait-based toxicant could be cost-effective for substantially reducing populations of wild pigs, but for elimination it may be most cost-effective to integrate additional management techniques following initial toxicant deployment. The nonlinear interaction of cost-effectiveness, initial population size, and reduction objective also emphasized the importance of considering the dynamics of space use and bait consumption for predicting effective baiting strategies. Although we used data for an acute toxicant and wild-pig consumption rates, our framework can be readily adapted to other vertebrate pest species and toxicant characteristics.
\end{abstract}

Keywords Toxicant $\cdot$ Bait $\cdot$ Cost-effectiveness $\cdot$ Population model $\cdot$ Decision-making tool $\cdot$ Wild pig

\section{Key message}

- Animal space use and bait-consumption rates determine effective baiting strategies for pest control.

- A spatially explicit model of consumption and control dynamics, based on field data, predicted cost-effectiveness of baiting strategies.

- Cost-effectiveness scaled nonlinearly with population density and control objective.

Communicated by C. Imholt.

Electronic supplementary material The online version of this article (https://doi.org/10.1007/s10340-020-01196-9) contains supplementary material, which is available to authorized users.

Kim M. Pepin

kim.m.pepin@aphis.usda.gov

1 National Wildlife Research Center, USDA-APHIS, 4101

Laporte Ave, Fort Collins, CO 80521, USA
- Considering space-use data alone in planning baiting strategies could lead to sub-optimal strategies, or strategies that don't meet management objectives.

- Considering the dynamic nature of bait visitation, consumption by the target species, and variation in management effort is important for planning cost-effective baiting strategies.

\section{Introduction}

Baiting is a common method to deliver pharmaceuticals to a target species for control of pests or diseases (Bengsen 2014; Campbell et al. 2006; Donlan et al. 2003; Gilbert et al. 2018; Hyngstrom and VerCauteren 1995; Savarie et al. 2001; Tompkins and Ramsey 2007). A primary challenge for managing populations of vertebrate pests with pharmaceuticals is determining the optimal density of baits to apply across an area, which depends on many factors including: attractiveness of bait, animal movement behavior, landscape 
heterogeneity, seasonality, efficacy of the bait, and duration of baiting effort. In general, it is suggested that in order to control pests using a bait-based strategy, spacing of baits should be within the radius of attraction to baits-i.e., the average distance between an animal's home range centroid and bait sites that they visit (Bengsen 2014; Snow et al. 2018; Tompkins and Ramsey 2007). Similar logic is used for planning aerial bait-drop strategies for vaccinating wild carnivores against rabies, where it is hypothesized that flight line spacing should aim to deliver multiple baits within an individual's core home range area (i.e., 50\% usage area, Berentsen et al. 2018). However, as animals have highly variable space-use patterns that depend on seasonal demographic dynamics, and because more effort is needed to locate individuals as populations decline, it could be misleading to predict optimal bait density from average home range size.

Quantitative models of bait visitation behavior can provide an efficient means for understanding and predicting how ecological complexities such as individual variation in movement and social structure determine the effectiveness of different baiting strategies. Deterministic population models have been useful in predicting the effects of toxicants on wild pig (Sus scrofa) population abundance (Hone 1992). This approach ignores heterogeneity in contact with bait and variation in the predicted time to elimination due to demographic stochasticity at low abundance. Deterministic population-level models also complicate the ability to account for the individual-level changes in bait status (consumed versus not consumed) that are occurring in the field due to local wild pig density and can be monitored with trail cameras or manually monitoring bait sites. In contrast, individual-based models can provide more accurate prediction in highly heterogeneous systems (Federico et al. 2013). Using an individual-based model, Tompkins and Ramsey (2007) showed that incorporation of individual-level space use and bait-encounter rates allowed for accurate prediction of the proportion of individual possums (Trichosurus vulpecula) that consumed biomarked bait at different baiting densities. They focused on bait consumption within 10 days following a single application of bait, but did not address objectives that could be influenced by longer-term baiting and demographic dynamics. In particular, locating individuals requires increasingly more effort as population density declines (Choquenot et al. 1999), such that bait-encounter rates decrease nonlinearly with decreasing population density or distance from baits (Snow et al. 2018). A framework that combines individual-level bait-encounter behavior with demographic dynamics would be a useful tool for predicting optimal long-term baiting strategies because in most systems long-term baiting is required to achieve the desired level of control.

Another important component of optimizing baiting strategies is comparing costs of different bait application strategies in space and time. In the absence of costs, the best strategy will be the one that removes a pest the fastest. Often, though, management strategies are based on available funds, highlighting the importance of restricting the optimal strategies to realistic possibilities by incorporating economic data (McMahon et al. 2010) or realized management patterns (Pepin et al. 2017a; Tompkins and Ramsey 2007). Management costs are typically not directly proportional to the density of target species because time to attract animals to bait (search effort) increases with decreasing density (Choquenot et al. 1999; Cowled et al. 2006). These nonlinear relationships of densities to costs can result in different predictions of optimal control strategies relative to cost-density relationships that are directly proportional (Davis et al. 2018). The most fundamental components of management costs are labor, equipment, and supplies. Almost completely unexplored is the effect of how costs of these components may change based on spatial strategies of controlling pest populations. For example, more fuel and labor costs are needed to conduct baiting at sites that are far apart versus close together. Thus, consideration of all associated costs based on the spatial strategy of baiting is important for planning optimal baiting strategies over large spatial areas.

Finally, another important consideration for optimizing baiting strategies is understanding how learned avoidance behavior by the target animals impacts the efficacy of control. Not all individuals will consume toxic baits or consume enough to succumb from the bait (e.g., Snow et al. 2018), and therefore sub-lethal dosing may occur. Furthermore, sub-lethal dosing can reduce the effectiveness of toxic baits over time via learned bait avoidance (Allsop et al. 2017). For some pest species, just a few remaining animals on the landscape can re-establish a population quickly (Morrison et al. 2007); thus, learned avoidance of toxic baits is important for managers to consider.

Our primary aim was to predict the density of bait sites needed to reduce pest populations throughout a range of targeted objectives at the lowest costs (optimal baiting strategy). Our secondary aim was to understand how toxic bait efficacy and avoidance by previously exposed (aversively conditioned) individuals might affect effectiveness and cost of the optimal strategy. We approached these objectives using a computational model with parameters relevant to ongoing development of a sodium nitrite-based toxicant for wild pigs (Cowled et al. 2006; Shapiro et al. 2016; Snow et al. 2017a). We integrated field data on wild pig space use near bait sites, rates of bait consumption and efficacy, data of wild pig demographics and social behavior, and realistic constraints on the distribution and use of toxic bait, into an individual-level population model. We hypothesized that optimal bait-site density would depend on both wild pig population density and the control objective (e.g., amount of 
population reduction that is desired) because attracting pigs to bait becomes more labor-intensive as density decreases. Thus, we predicted that the optimal density of bait sites would be higher in low-density relative to high-density populations to reach similar proportional reduction objectives. Lastly, we predicted that avoidance would present a major challenge for reaching population reduction objectives near elimination but that some avoidance may be tolerated when the population reduction objective is less stringent, allowing some educated individuals to be left on the landscape. Our model provides a tool for predicting optimization of toxic baiting criteria using bait sites while considering the movement and bait uptake behavior of the target species.

\section{Methods}

\section{Study species}

Invasive wild pigs cause extensive agricultural, ecological, and property damage (Anderson et al. 2016; Hone 1995; Pimentel 2007; Pimentel et al. 2000), which also occurs in their native range (Massei and Genov 2004; Schley et al. 2008). To effectively reduce wild pig populations and damage, managers must be capable of sustained and dramatic reductions (Keuling et al. 2013; Mayer 2009; Pepin et al. $2017 \mathrm{a}, \mathrm{b})$. Methods of control have included toxicants, aerial gunning, trap and remove, hunting, and sharp shooting (Da Rosa et al. 2018; Mayer and Brisbin 2009; Queensland 2008). The effectiveness of different methods varies depending on habitat, weather, and population density (Muir and McEwen 2007; Steen 2006). Toxicants are thought to be cost-effective (Queensland 2008), particularly in certain habitat and weather conditions where other methods may be less effective (Cowled et al. 2008). Several countries have sought to develop a new toxic bait containing the acute active ingredient, sodium nitrite, (Lapidge et al. 2012; Shapiro et al. 2016; Snow et al. 2017a) to address animal welfare concerns with previously developed toxicants such as sodium fluoroacetate (1080), warfarin, and yellow phosphorus, which have been used to varying degrees in Australia (Cowled et al. 2008). Sodium nitrite is considered humane due to its rapid lethality (Cowled et al. 2008) and has potential to economically remove large proportions of populations of wild pigs in treated areas (Lavelle et al. 2018b; Snow et al. 2017a, 2018). Prototype sodium nitrite-based baits achieved 89-95\% lethality in pen studies with wild pigs (Shapiro et al. 2016; Snow et al. 2017a). Field studies have shown that attraction distances to bait sites can be highly variable among individuals and sexes depending on individual-level variation in space-use behavior (Lavelle et al. 2018b). Most wild pigs visit bait sites within $0.75-1.5 \mathrm{~km}$ from the centers of their home ranges, although may be attracted from $>3 \mathrm{~km}$ away (Lavelle et al. 2018b; Snow et al. 2018). A wild pigspecific bait station is being developed to restrict access to toxic bait by non-target species (Lavelle et al. 2018a; Snow et al. 2017b) and requires a non-toxic pre-bait training period of $\sim 15$ days for wild pigs to become accustomed to using it (Lavelle et al. 2018b). Although sodium nitrite-based toxic bait delivery systems are still being tested and optimized to evaluate/minimize potential non-target losses (Snow et al. $2017 \mathrm{c}, 2019$ ), it is useful to begin evaluating the effectiveness of potential implementation strategies to help guide experimental design of field studies, manage expectations of practitioners, and to have an off-the shelf planning tool when the product is ready.

\section{Modeling approach}

We developed a spatially explicit individual-based model to account for individual-level variation in space use (Kay et al. 2017; Lavelle et al. 2018b), and thus the propensity to visit bait sites. We allowed individuals to have different movement capacity to account for individual-level stochasticity in bait uptake. We focused on determining cost-effective baiting densities for empirical distributions of pig movement and bait uptake using a theoretical toxic bait product with a negligible amount of non-target mortality. We describe the model structure and component algorithms in detail using the ODD Protocol (Grimm et al. 2010) in the supplementary text and give a conceptual overview below.

\section{Determining the optimal strategy}

We evaluated model output descriptively relative to achieving a range of management objectives-i.e., reduction of population abundance by a target amount. Effectiveness for a given strategy (set of parameters) was determined by the proportion of 100 stochastic simulations that reached the management objective within 5 years (probability of reaching objective). The optimal strategy for bait density was determined as the one that had the lowest cost (\$USD) per unit of effectiveness (total cost/probability of reaching the objective). We also descriptively summarized the amount of time it took to reach the management objective and the total costs for each parameter set. We describe how cost data were incorporated below the model description.

\section{Individual-based model}

The model and analyses were developed in MATLAB programming language (Version R2018a, Mathworks, Natick, MA, USA). The purpose of the model is twofold: 1) to predict the density of bait sites needed to reduce a wild pig population by a target proportion at the lowest cost, and 2) to understand how bait avoidance by previously 
exposed individuals affects cost-effectiveness for different population reduction objectives. The model included demographic dynamics of the pig population, baiting activities, and spatial movements of both wild pigs and bait sites (Fig. S1). Attributes for individual pigs included: age, sex, social group, age at dispersal, longevity, home range radius, movement distance, home range centroid, bait exposure status, and carrying capacity of their home grid cell. For females, we also tracked reproductive status, gestation time, and time since last birthing event. Pig states were either alive and not yet exposed to toxic bait or alive and recovered from toxic bait exposure (based on bait efficacy in pen trails; Snow et al. 2017a). Pigs that died from toxic bait exposure were permanently removed from the population.

Bait sites had three states: (1) 'locating', where non-toxic pre-bait (e.g., corn) is placed on the ground to determine if wild pigs are in the area, but no bait station is present, (2) 'training', where wild pigs have been located and a bait station containing non-toxic pre-bait has been placed. During this phase wild pigs become accustomed to using the bait station. Finally, state (3) is the 'toxic' phase, where toxic bait is used allowing for pigs to be killed. For each bait site we tracked: the state, the number of pigs that visited per day, and the location of the bait sites on the habitat grid in continuous space.

Pig daily movements occurred in continuous space, but the habitat grid that defined abundance consisted of 225 discrete $4 \mathrm{~km}^{2}$ cells (total area $900 \mathrm{~km}^{2}$ ). We examined landscapes with densities of $1,3,5$, or $10 \mathrm{pigs} / \mathrm{km}^{2}$ (i.e., abundances at biological carrying capacity of $900,2700,4500$, or 9000 pigs), which is similar to density variation observed in southern USA (Davis et al. 2017; Keiter et al. 2017). For this analysis we assumed a homogenous distribution of density (i.e., without variation in density due to landscape factors) in order to isolate the effects of animal density from heterogeneity in density. We also assumed that interactions with conspecifics did not affect visitation rates to bait sites.

All runs were begun after a 31-year burn-in period (no management) where populations were initialized at $10 \%$ of carrying capacity and allowed to increase until they reached carrying capacity (Fig. S2). The reason for the burn-in period was to allow enough time for the age, sex, and social structure to establish without influence from initial conditions. After the burn-in period, management treatments were initiated and the simulations progressed for an additional 5 years. The following events occurred in the model on a daily time step:

1. Bait-site dynamics, which included visits of pigs to each bait site, effects of the bait on individual pigs (kill or not), updates of the bait-site status, updates of labor time and costs, and relocation of bait sites as needed.
2. Natal dispersal, where pigs that reached their age of dispersal relocated to new home range centroids.

3. Social structure, where independent females joined nearby family groups and oversized groups were divided in half with one group moving to a new home range centroid (according to a process similar to natal dispersal).

4. Density-dependent immigration, where new pigs from an exogenous population migrated into the area.

5. Conception, births, and natural mortality, where reproductively active females in grid cells below carrying capacity were allowed to conceive and then birth litters following a gestation period. Conception probability was density-dependent (Fig. S1). Pigs at the age of natural longevity (i.e., longevity in the absence of control or hunting; (Jezierski 1977)) were removed from the population.

Implementation details of the demographic and bait visitation processes, all parameter values, and model assumptions are summarized in the Supplementary Text. In previous work we examined sensitivity of the demographic model to demographic parameters (Pepin et al. 2017a). Here, we developed baiting processes and examined sensitivity to three bait-related parameters: (1) the density of bait sites in relation to wild pig density—referred to as 'pigs/bait site at initiation', (2) the efficacy of toxic bait-the proportion of pigs killed after bait consumption, and (3) avoidance-proportion of wild pigs that consumed bait but did not die and avoid the bait in the future.

\section{Costs}

For each run, costs were tracked in 4 categories: (1) initial costs for equipment (based on the maximum number of bait sites employed simultaneously and the cost per bait station), (2) salary and supplies costs for setting up or removing bait sites, (3) daily salary and supplies costs for running nontoxic pre-baiting and post-baiting, and (4) daily salary and supplies costs for running bait sites with toxic bait. For each of these categories we assumed that costs increased linearly with the number of bait sites and average distance among them. Costs for the bait stations were only accrued initially, after which they were reused at no additional cost. Costs of non-toxic and toxic bait were factored into every category. For each category, the per day costs $\left(c_{t}\right)$ were calculated as: $c_{t}=b_{1}+m \cdot b_{1} \cdot N_{\mathrm{b}, t} \cdot d_{\mathrm{b}, t}$, where $b_{1}$ is the labor and supplies cost for baiting one site, $N_{\mathrm{b}, t}$ is the total number of bait sites at time $t, d_{\mathrm{b}, t}$ is the average pairwise distance among all bait sites at time $t$, and $m$ is the slope of the relationship between cost and the interaction of (bait site number $\times$ spatial area). For example, if the cost of running one bait site for a day with placebo bait is $\$ 10$, and $m=0.5$, the cost to run 5 bait stations with placebo bait per day spaced at 
$1 \mathrm{~km}^{2}$ on average would be: $\$ 10+(0.5 \cdot \$ 10 \cdot 5$ bait stations $\left.\cdot 1 \mathrm{~km}^{2}\right)=\$ 35$. The total cost at each time step was the sum of all 4 categories, and the total cost for the whole run was the sum across time and categories. We chose the following fixed parameters in each category (shown as $\left[b_{1}, m\right]$ ): (1) $\$ 100$ (equipment costs per bait station-no $m$ parameter), (2) $[\$ 15,0.05],(3)[\$ 10,0.05]$, and 4) [\$50, 0.05] based on field work related to development of bait stations and toxic bait delivery (Lavelle et al. 2018b; Snow et al. 2018).

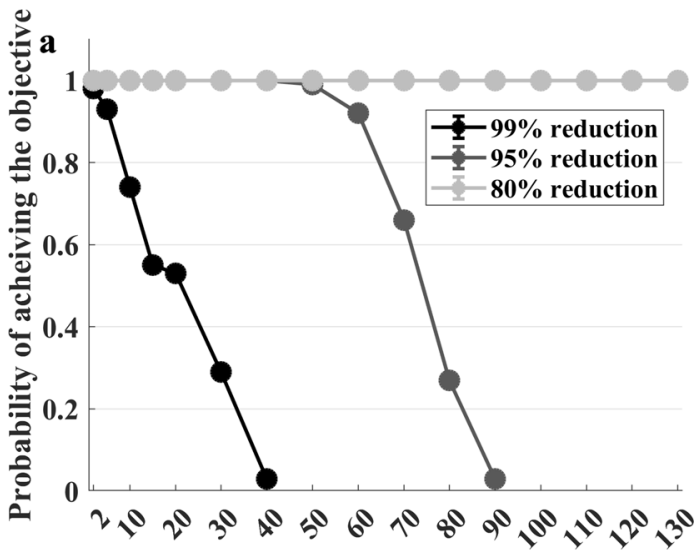

Pigs/bait station at initiation of control

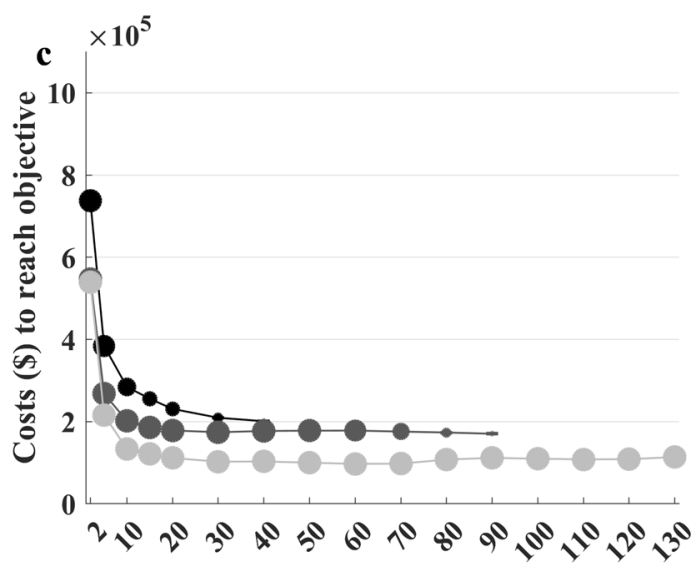

Pigs/bait station at initiation of control $\rightarrow$ Decreasing bait station density (bait stations $\left./ \mathbf{k m}^{2}\right) \rightarrow$

\section{Results}

\section{Evaluation of bait-station density}

An acutely toxic bait was effective at reducing the population by $80 \%$ over a wide range of bait-station densities (Fig. 1, top left). However, if the management target was 99\% reduction, then effectiveness reduced rapidly when lower bait-station density strategies were used (i.e., increase in pigs/bait station- $X$-axes of Fig. 1). In contrast, cost per unit of effectiveness was highest at the high and low ranges of bait-station density, meaning that these ranges of bait-station density were not as cost-effective as intermediate values of bait-station density (Fig. 1). The optimal baiting strategy

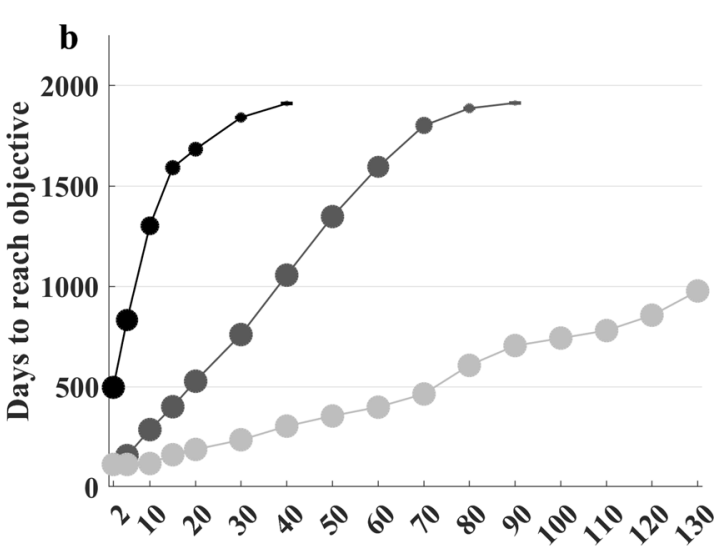

Pigs/bait station at initiation of control

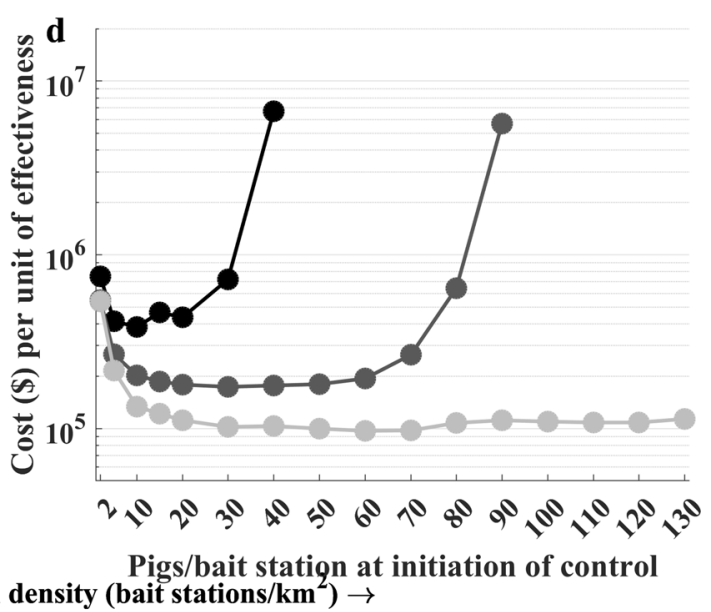

Fig. 1 Effects of bait-station density on metrics of effectiveness and efficiency. Each point is an average of 100 stochastic simulations ( $95 \%$ confidence intervals are contained within the large points). $X$-axis values are the number of pigs per bait station at initiation of the baiting treatments-a measure of bait-station density. Note, baitstation density decreases from left to right on the $X$-axis. For 3 pigs/ $\mathrm{km}^{2}$, a range of $2-130$ pigs per bait station ( $X$-axis range) equates to a range of 1350-21 bait stations at initiation of control on average in a $900 \mathrm{~km}^{2}$ area, which is a bait station density of $1.5-0.023$ bait stations per $\mathrm{km}^{2}$, or 1 bait box per $0.67-43.5 \mathrm{~km}^{2}$. In $\mathbf{b}, \mathbf{c}$ plots only simulations that reached the management target were included in the average. Size of the points are scaled to the number of simulations included in the average. Each plot shows results for 3 different management targets (see legend in a). Fixed conditions: 3 pigs $/ \mathrm{km}^{2}$, no avoidance, toxic bait efficacy $=0.93$ 
also depended on the management objective. If the objective was $99 \%$ reduction (black line in Fig. 1, bottom right), then the optimal strategy was to target a bait-station density of 5-20 pigs/station on a landscape with an average density of 3 pigs $/ \mathrm{km}^{2}$ (corresponding to $0.15-0.6$ bait stations $/ \mathrm{km}^{2}$ or 1 bait station $/ 1.7-6.7 \mathrm{~km}^{2}$ ). In contrast, if the objective was only $80 \%$ reduction (light gray line in Fig. 1, bottom right), then the optimal strategy was to target a bait-station density of 30-70 pigs/bait station on a landscape of the same average density (corresponding to $0.043-0.1$ bait stations $/ \mathrm{km}^{2}$ or 1 bait station $/ 10-23 \mathrm{~km}^{2}$ ).

As expected, more bait sites per pig (higher baiting densities) were needed to control low-density populations
(Figs. 2, 3), because these populations were more sparse and because it required more bait stations to locate and attract individuals to bait. However, the range of effective baiting densities was not directly proportional to population density: populations with $1 \mathrm{pig} / \mathrm{km}^{2}$ required much higher bait-station densities to reduce populations by $95 \%$, whereas populations of 3 or $5 \mathrm{pigs} / \mathrm{km}^{2}$ required similar baiting densities, and populations of $10 \mathrm{pigs} / \mathrm{km}^{2}$ required much lower baiting densities (Fig. 2).

Similar patterns occurred in terms of optimal strategies (cost per unit of effectiveness): at densities of 3-5 pigs $/ \mathrm{km}^{2}$ optimal baiting densities were similar, whereas at lower
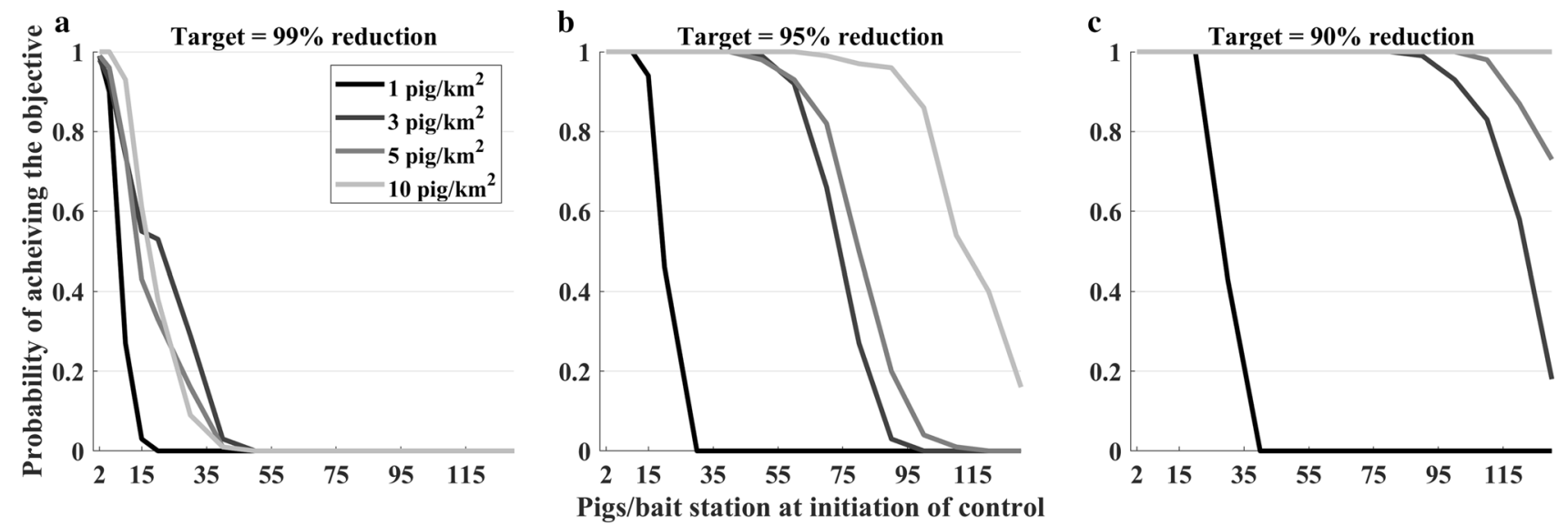

Fig. 2 Effects of bait-station density on effectiveness for different population densities of wild pigs. Lines show the average relationship (from 100 stochastic simulations) for different conditions of wild pig population density (indicated in the legend). $X$-axes are as in Fig. 1.
Each plot shows the results for a different management objective (indicated at the top of plots). Fixed conditions: no avoidance, toxic bait efficacy $=0.93$
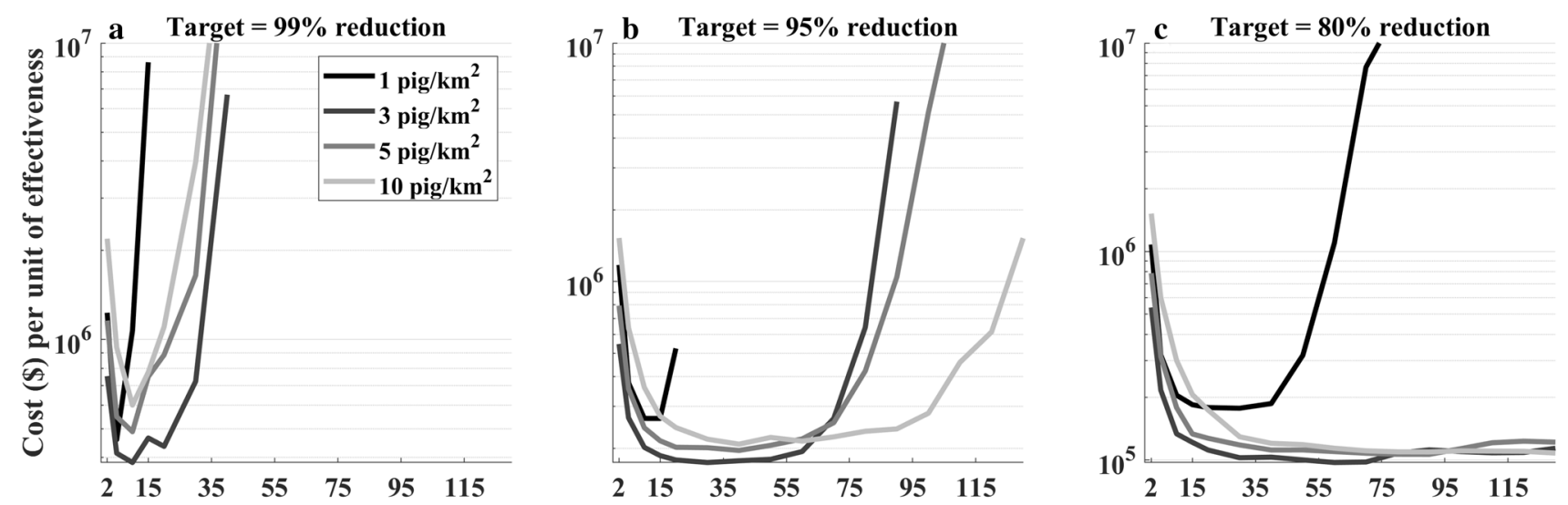

Pigs/bait station at initiation of control

Fig. 3 Effects of bait-station density on cost per unit of effectiveness for different population densities of wild pigs. Lines show the average relationship (from 100 stochastic simulations) for different conditions of wild pig population density (indicated in the legend). $X$-axes are as in Fig. 1. Each plot shows the results for a different management objective (indicated at the top of plots). Fixed conditions: no avoidance, toxic bait efficacy $=0.93$ 
densities and higher densities of wild pigs the optimal baiting density was quite different (Fig. 3).

\section{Effects of avoidance behavior and toxic bait efficacy}

With a management objective of $80 \%$ reduction of abundance, effectiveness and cost per unit of effectiveness were not very sensitive to the efficacy of the toxic bait and avoidance behavior (Figs. 4, 5). For example, even when toxic bait efficacy was only $51 \%$ (i.e., $49 \%$ consumed and recovered), and up to $70 \%$ of the recovered $49 \%$ (i.e., $34 \%$ 'educated') avoided baits in the future, the management objective could still be achieved in $>90 \%$ of simulations (Fig. 4, bottom right). However, this type of inefficiency did result in an increase in the cost per unit of effectiveness (Fig. 5, bottom right). Additionally, if the bait efficacy was $93 \%$ on average (as in Snow et al. 2017a), then effectiveness and cost per unit of effectiveness were unaffected even if all $7 \%$ of recovered individuals avoided re-exposure to the toxic bait (right side of gray lines in Figs. 4, 5, bottom left plots). In contrast, as the management objective approached elimination (99\% reduction), bait efficacy and avoidance behavior strongly determined effectiveness and cost per unit of effectiveness (Figs. 4, 5). To achieve a 99\% reduction in a population with $1 \mathrm{pig} / \mathrm{km}^{2}$, the highest levels of effectiveness and cost per unit of effectiveness were achieved when avoidance following consumption was $<30 \%$ and efficacy of the toxic bait efficacy was $>80 \%$ (meaning that $30 \%$ of $20 \%=6 \%$, was the maximum tolerance level for 'resistance' to the toxic bait when the management objective was $99 \%$ reduction; Figs. 4, 5).

\section{Discussion}

Using a data-informed population model of wild-pig demographic dynamics and bait-consumption behavior, we developed a tool for inferring optimal baiting densities for achieving management objectives using a toxicant. If we calculate optimal bait density using the average radius of attraction
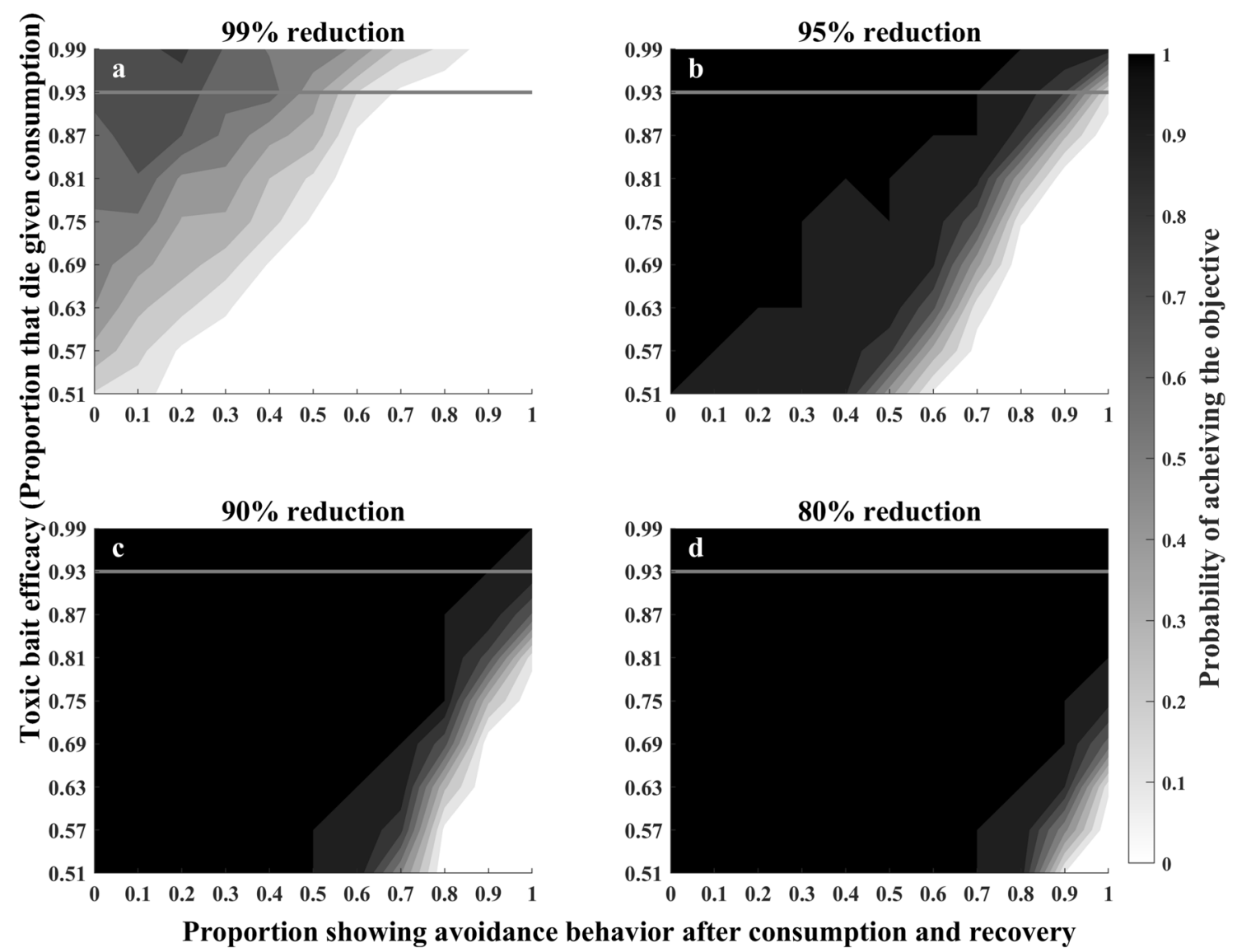

Fig. 4 Effects of toxic bait efficacy ( $Y$-axes) and avoidance behavior ( $X$-axes) on effectiveness-the probability of reaching the management objective out of 100 stochastic simulations (color bar). White corresponds to never reaching the management objective $(0 \%$ effec-

tiveness), while black corresponds to always reaching the objective (100\% effectiveness). The horizontal gray line indicates the baseline parameter for toxic bait efficacy that was used in Figs. 1, 2 and 3. Fixed conditions: $1 \mathrm{pig} / \mathrm{km}^{2}, 15$ pigs per bait station at initiation 

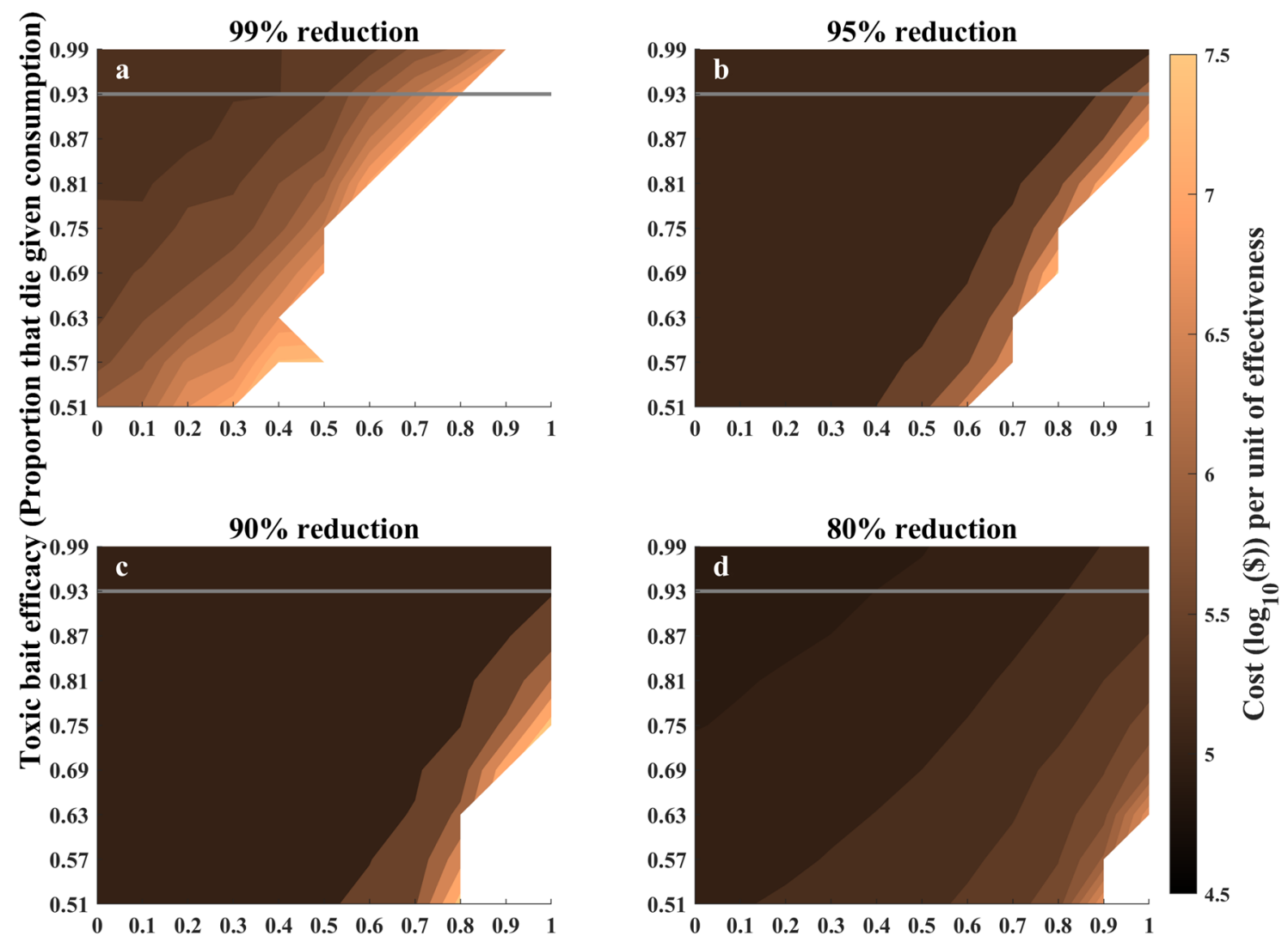

Proportion showing avoidance behavior after consumption and recovery

Fig. 5 Effects of toxic bait efficacy ( $Y$-axes) and avoidance behavior ( $X$-axes) on cost per unit of effectiveness on a $\log _{10}$ scale (color bar). Each plot shows the average outcome (from 100 stochastic simulations) under a different management objective. White areas represent parameter sets that never reached the management objective $(0 \%$

( $2 \mathrm{~km}$, Snow et al. 2018) data alone, we might predict that a density of $\geq 0.08$ bait sites per $\mathrm{km}^{2}[\geq 1$ bait site per circular home range: $\pi(2)^{2}=12.6 \mathrm{~km}^{2}$ ] could be sufficient to have at least 1 visited bait site per individual on average. But, this calculation would not factor in how effort changes as a function of density or individual-level variation in visitation and consumption as a function of distance. By incorporating costs and demographics, we found that the most costeffective baiting strategy depends strongly on the objective and population density, suggesting that calculations based on average space use alone are likely not accurate because they would be constant regardless of the objective. This illustrates the importance of accounting for spatiotemporal population dynamics, and how they interact with cost and management effort, when planning optimal baiting strategies. Basing recommendations only on attraction distance to baits might not be enough for cost-effective planning.

In our simulations, an acutely toxic bait for wild pigs was very effective at reducing abundance substantially, but was not cost-effective for transitioning populations from low effectiveness), while black corresponds to always reaching the objective (100\% effectiveness). The horizontal gray line indicates the baseline parameter for toxic bait efficacy that was used in Figs. 1, 2 and 3. Fixed conditions: $1 \mathrm{pig} / \mathrm{km}^{2}, 15$ pigs per bait station at initiation

abundance to elimination. In low-density populations, reducing the population by $99 \%$ involves driving the population to a lower absolute abundance than necessary in high-density populations. Thus, the management objective of $99 \%$ reduction was not achieved for most bait-station densities for the 1 $\mathrm{pig} / \mathrm{km}^{2}$ conditions, but could be achieved over a wider range of bait-station densities for the conditions with 3-10 pigs/ $\mathrm{km}^{2}$. For example, if the initial abundance was 900, a $99 \%$ reduction means that only 9 pigs are remaining, whereas if the initial abundance is $2700-9000\left(3-10 \mathrm{pigs} / \mathrm{km}^{2}\right)$, a $99 \%$ reduction would mean that $27-90$ wild pigs remain on the landscape. As effort increases exponentially to locate pigs at low abundance, removing the extra 81 wild pigs $(90-9=81)$ at low density was exponentially more costly than stopping at an abundance of 90 wild pigs. This disproportionate effort of removing final remaining individuals in eradication campaigns is well recognized and often requires integrating additional management strategies to be effective (McCann and Garcelon 2008; Parkes et al. 2010). Including additional strategies to target individuals once abundance 
drops below a low-abundance threshold could provide guidelines for more cost-effective management strategies when the objective is elimination.

We also showed that managers could apply a wide range of bait-station densities cost-effectively if the management target was a large reduction in abundance (e.g., 80\%) but not elimination. We considered cost-effectiveness as a function of the probability that an abundance reduction target was reached within a fixed period of time (5 years). If the management objective (effectiveness) is framed in terms of how much the population is reduced or how long it takes to reach a particular abundance or agricultural damage-reduction objective, the range over which cost-effectiveness is highest could be reduced. Additionally, our measure of cost included implementation costs but not damage costs. Costs of running fewer bait stations for longer seemed similar to running more bait stations for shorter time over a wide range of bait-station densities. We may expect to see a finer resolution of optimal bait-station density if we had considered damage costs in the overall cost-effectiveness (e.g., Davis et al. 2018; Hone et al. 2017; Yokomizo et al. 2009). This is because when more individuals are left on the landscape longer, more damage can occur, which is especially true when the relationship between density and damage is exponential (Davis et al. 2018; Yokomizo et al. 2009). For example, when each additional individual on the landscape causes exponentially more damage, costs of cheaper but slower control could be more expensive overall due to the additional damage costs that are accrued from slower control (Davis et al. 2018; Yokomizo et al. 2009). A second layer of complexity to consider when including damage costs is the seasonality of damage. Visitation to crops can vary seasonally in wild pigs (Kay et al. 2017) due to variability in crop and natural-forage availability. Thus, when considering damage costs in optimal baiting strategy, the predicted optimal density could also vary seasonally. Incorporating field measures of seasonal variation in crop damage could refine predictions of the cost-effectiveness of baiting strategies, by highlighting how baiting strategies need to be adjusted seasonally to be most cost-effective.

Costs of implementing a particular management strategy depend not only on how densely baiting is done, but also on the total spatial area. It takes longer and thus is more expensive to maintain 10 bait sites that are farther apart relative to 10 that are closer together. Our cost analyses accounted for the increased cost with spatial area, but we assumed that the costs associated with running bait sites across farther distances (or at higher densities) only increased due to hourly salary costs. In fact, running far-apart or high-density baiting strategies will also require more personnel individuals working each day because a given person is limited in the amount of bait sites they can visit in 1 day. Personnel could thus be a limiting factor in far-apart or high-density strategies because it might not be possible to afford paying for additional labor costs. Considering the potential additional costs from extra personnel and an upper limit on a feasible number of personnel could be an important future direction for refining optimal baiting strategies in space.

Pests may avoid toxic bait to some degree after exposure and recovery from a sub-lethal dose (Bengsen 2014; Hickling et al. 1999), but the impacts on toxicant effectiveness by aversion have not been studied in wild pigs (Allsop et al. 2017). Our results showed that if the management target is an $80 \%$ reduction or less, the system is fairly robust to bait aversion and bait efficacy. But, the combination of aversion and efficacy becomes more important as the management objective becomes more stringent (i.e., $>80 \%$ reduction). Thus, if sub-lethal dosing and aversion are prevalent, additional management methods will need to be integrated into the program to eliminate remaining individuals once the population drops below $20 \%$ its pre-treatment abundance. We examined fixed values for aversion and efficacy, but if uncertainty in these parameters is quantified, it could also be useful to predict cost-effectiveness while accounting for uncertainty in these parameters. That would provide a more accurate portrayal of uncertainty in reaching the management objective for better consideration of risks when choosing the optimal baiting strategy.

We used bait visitation and consumption rates from a single study site (Snow et al. 2018) to account for variation in the probability that wild pigs visit bait stations. Our method considered effects of age, sex, family group structure, and distance between bait stations and home range centroids of individuals. The study by Snow et al. (2018) was conducted on the Edwards Plateau and Blackland Prairie ecoregions of south-central Texas where dominant vegetation communities consisted of cedar-oak woodlands and grasslands on rocky soils and limestone outcrops. Baits were placed at sites that showed evidence of usage by wild pigs, and pigs from these sites were collared. Thus the movement data used in our study reflects movement variation under these conditions. However, visitation rates of animals to food-based baits are known to fluctuate in space and time due to the quality and availability of natural forage, seasonal changes in energy requirements of individuals, anthropomorphic disturbance, landscape structure, weather, and other factors (Krijger et al. 2017; Kay et al. 2017; Lemel et al. 2002; Patergnani et al. 2010). Thus, the probability of bait consumption could be lower under some conditions than predicted by the data we used, which would increase the overall costs per unit of effectiveness. Testing the effects of weather, seasonality, conspecific interactions, and landscape on variation in bait-consumption rates is an important direction for future field research. Recently mechanistic movement models have been used to describe wild pig movement trajectories and crop visitation on a variety of landscapes (Wilber et al. 
2020). An especially useful future direction is to incorporate mechanistic resource-based movement (i.e., derived from GPS data as in Wilber et al. 2020) and realistic landscape layers into our modeling framework to predict how particular landscape conditions affect cost-effectiveness and determine the optimal mix of strategies for minimizing the costs per unit of effectiveness in different landscapes. This methodology could incorporate seasonal or weather-based changes in movement behavior around bait sites (Raynor et al. 2017) as well as effects of conspecific interactions due to animal density and resource competition (Dundas et al. 2014) and would provide a quantitative framework for predicting optimal bait placement on the landscape along with bait density, which is known to be an important determinant of consumption rates (Patergnani et al. 2010).

A longer-term consideration that could be included in future work on toxicant use strategies is genetic resistance. Resistance can arise following long-term use of some toxicants (Pelz et al. 2005; Twigg et al. 2002). Individuals that consume a toxicant but do not die are selected and their genes can become more prevalent in future generations. Thus, future generations have a larger proportion of individuals that are less susceptible to toxic bait. We modeled toxicant application over generations for up to 5 years which could be long enough for genetic resistance to begin developing in a population. Depending on the genetic basis and strength of resistance, resistance effects could be more severe than aversion because the hard selection of the toxicant could increase the frequency of resistance while avoidance due to sub-lethal dosing may fluctuate around a similar level according to variation in habitat and delivery methods. Thus in populations where genetic resistance is likely to develop, it would be useful to consider the resistance process for determining optimal management strategies (Desvars-Larrive et al. 2019). It could be that higher densities of baits and very high efficacies are required to reach the management objective, and a mix of integrated management strategies could be required if the objective is elimination. While our parameters were specific to the ecology of wild pigs and an acutely toxic bait, our methodology is easily amenable to other species and bait characteristics.

We used a distribution of visitation and bait-consumption probabilities, based on field measures for wild pigs (Snow et al. 2018), to inform the attraction distance of pigs to bait. This data set could readily be replaced with similar field data from any other species. Likewise, we used pre-baiting time frames that have been shown to be effective for wild pigs (Snow et al. 2018), and toxic-bait times that are appropriate for an acutely toxic bait (i.e., only 2-day intervals). These could easily be extended in the model to examine optimal baiting strategies using a different pre-baiting time or sloweracting toxin. Decreased pre-baiting times would decrease the rates of subsequent toxic bait consumption because we used the shortest time frame that led to most wild pigs consuming bait. However, cost-effectiveness would be increased in a system where a species could be 'trained' to use a bait site effectively via a shorter pre-baiting period, which could mean that lower density baiting strategies might be effective. To apply our approach for a slower-acting toxin, one would simply extend the toxic baiting period. This would likely decrease cost-effectiveness, depending on the cost of toxic bait and length of time that monitoring at bait sites is required to ensure success.

Similarly, we assumed that the toxic bait delivery mechanism led to a negligible amount of non-target mortality. For situations where the bait matrix or delivery mechanism has a substantial risk of non-target mortality, the delivery protocol may need to be modified from the protocol we present here such that it is less efficient at killing the target species (i.e., less time available or using a device that is less efficient). Using a less efficient baiting protocol costs would increase per unit of effectiveness. Thus, while the qualitative insight we gained from our model may be generally applicable, the absolute values of cost-effectiveness and recommendations for bait-station density will vary depending on baiting protocol and other ecological conditions (as described above). Our methodology provides an off-the-shelf tool that can be readily adjusted with context-dependent host movement and baiting protocol data to help guide cost-effective implementation of baiting with toxicants. By helping to understand how multiple dynamical ecological processes interact, our framework can also be used to help guide experimental design of studies aimed at optimizing delivery of toxicants.

\section{Conclusion}

The use of toxic bait to control feral swine will be most costeffective when applied to reduce high-density populations by substantial amounts, but may benefit by the addition of other management strategies such as sharp shooting or aerial gunning when the objective is elimination. For large reductions in abundance (not more than $90 \%$ ), we also found that the system is robust to a wide range of baiting strategies as long as personnel are available. The absolute range of costeffective baiting strategies does depend on absolute abundance-i.e., if the management target involves a decrease in absolute abundance below 180 individuals, for example (for an $80 \%$ reduction: 900 total $\times 0.2=180$ individuals), only high baiting densities were cost-effective. However, reducing the population from 2700 to 540 (also an $80 \%$ reduction) could be achieved over a wide range of baiting densities because locating individuals does not require as much effort when abundance is as high as $\mathbf{5 4 0}$ individuals. The toxicant delivery was also effective over a wide range of values for post-exposure avoidance and toxic bait efficacy, suggesting 
that some level of inefficiency from avoidance and efficacy can be tolerated. However, tolerance of these inefficiencies depended strongly on the management objective, highlighting that application of this tool should consider levels of avoidance and bait efficacy for planning appropriate management targets. Most generally, our results suggest that using space-use data alone to plan optimal baiting strategies could lead to sub-optimal strategies, or even strategies that are unlikely to meet the management objective. Methods that consider the dynamic nature of bait visitation and consumption, and management effort, are important for planning effective use of bait-based control tools.

\section{Author contributions}

KMP, NPS, KCV conceived the study. KMP developed the model, performed the analyses, and wrote the first draft. All authors edited subsequent drafts.

Funding This work was supported by the United States Department of Agriculture, Animal and Plant Health Inspection Service's National Feral Swine Damage Management Program.

\section{Compliance with ethical standards}

Ethical approval This article does not contain any studies with animals performed by any of the authors.

Conflict of interest All authors declare that they have no conflicts of interest.

\section{References}

Allsop SE, Dundas SJ, Adams PJ, Kreplins TL, Bateman PW, Fleming PA (2017) Reduced efficacy of baiting programs for invasive species: some mechanisms and management implications. Pac Conserv Biol 23:240-257

Anderson A, Slootmaker C, Harper E, Holderieath J, Shwiff SA (2016) Economic estimates of feral swine damage and control in 11 US states. Crop Prot 89:89-94

Barrett RH (1978) The feral hog on the dye creek ranch, California. Hilgardia 46:283-355

Bengsen A (2014) Effects of coordinated poison-baiting programs on survival and abundance in two red fox populations. Wildl Res 41:194-202

Berentsen AR et al (2018) Seroconversion of raccoons following two oral rabies vaccination baiting strategies. J Wildl Manage $82: 226-231$

Bieber C, Ruf T (2005) Population dynamics in wild boar Sus scrofa: ecology, elasticity of growth rate and implications for the management of pulsed resource consumers. J Appl Ecol 42:1203-1213
Campbell TA, Lapidge SJ, Long DB (2006) Using baits to deliver pharmaceuticals to feral swine in southern Texas. Wildl Soc Bull 34:1184-1189

Choquenot D, Hone J, Saunders G (1999) Using aspects of predatorprey theory to evaluate helicopter shooting for feral pig control. Wildl Res 26:251-261

Cowled BD, Lapidge SJ, Hampton JO, Spencer PBS (2006) Measuring the demographic and genetic effects of pest control in a highly persecuted feral pig population. J Wildl Manage 70:1690-1697

Cowled BD, Elsworth P, Lapidge SJ (2008) Additional toxins for feral pig (Sus scrofa) control: identifying and testing Achilles' heels. Wildl Res 35:651-662

Da Rosa CA, Wallau MO, Pedrosa F (2018) Hunting as the main technique used to control wild pigs in Brazil. Wildl Soc Bull 42:111-118

Davis AJ, Leland B, Bodenchuk M, VerCauteren KC, Pepin KM (2017) Estimating population density for disease risk assessment: the importance of understanding the area of influence of traps using wild pigs as an example. Prev Vet Med 141:33-37

Davis AJ, Leland BR, Bodenchuk MJ, VerCauteren KC, Pepin KM (2018) Costs and effectiveness of damage management of an overabundant species (Sus scrofa) using aerial gunning. Wildl Res 45:696-705

Desvars-Larrive A, Hammed A, Hodroge A, Berny P, Benoit E, Lattard V, Cosson J (2019) Population genetics and genotyping as tools for planning rat management programes. J Pest Sci 92:691-705

Donlan CJ, Howald GR, Tershy BR, Croll DA (2003) Evaluating alternative rodenticides for island conservation: roof rat eradication from the San Jorge Islands, Mexico. Biol Conserv 114:29-34

Dundas SJ, Adams PJ, Fleming PA (2014) First in, first served: uptake of 1080 poison fox baits in south-west Western Australia. Wildl Res 41:117-126

Federico P, Gross LJ, Lenhart S, Ryan D (2013) Optimal control in individual-based models: implications from aggregated methods. Am Nat 181:64-77

Gabor TM, Hellgren EC, Van Den Bussche RA, Silvy NJ (1999) Demography, sociospatial behaviour and genetics of feral pigs (Sus scrofa) in a semi-arid environment. J Zool Lond 247:311-322

Gethoeffer F, Sodeikat G, Pohlmeyer K (2007) Reproductive parameters of wild boar (Sus scrofa) in three different parts of Germany. Euro J Wildl Res 53:287-297

Gilbert A, Johnson S, Walker N, Wickham C, Beath A, VerCauteren K (2018) Efficacy of Ontario Rabies Vaccine Baits (ONRAB) against rabies infection in raccoons. Vaccine 36:4919-4926

Grimm V, Berger U, DeAngelis DL, Polhill JG, Giske J, Railsback SF (2010) The ODD protocol a review and first update. Ecol Model 221:2760-2768

Henry VG (1968) Length of estrous cycle and gestation in European wild hogs. J Wildl Manage 32:406-408

Hickling GJ, Henderson RJ, Thomas MCC (1999) Poisoning mammalian pests can have unintended consequences for future control: two case studies. N Z J Ecol 23:267-273

Hone J (1992) Modeling of poisoning for vertebrate pest-control, with emphasis on poisoning feral pigs. Ecol Model 62:311-327

Hone J (1995) Spatial and temporal aspects of vertebrate pest damage with emphasis on feral pigs. J Appl Ecol 32:311-319

Hone J, Drake VA, Krebs CJ (2017) The effort-outcomes relationship in applied ecology: evaluation and implications. Bioscience 67:845-852

Hyngstrom SE, VerCauteren KC (1995) Vertebrate pest management in grain storage facilities vol stored product management. Oklahoma State University Cooperative Extension, Stillwater, Oklahoma

Jezierski W (1977) Longevity and mortality rate in a population of wild boar. Acta Theriol 22:337-348 
Kay SL et al (2017) Quantifying drivers of wild pig movement across multiple spatial and temporal scales. Mov Ecol 5:14

Keiter DA, Davis AJ, Rhodes OE, Cunningham FL, Kilgo JC, Pepin KM, Beasley JC (2017) Effects of scale of movement, detection probability, and true population density on common methods of estimating population density. Sci Rep 7:9446

Keuling O, Lauterbach K, Stier N, Roth M (2010) Hunter feedback of individually marker wild boar Sus scrofa L.: dispersal and efficiency of hunting in northeastern Germany. Euro J Wildl Res 56:159-167

Keuling O et al (2013) Mortality rates of wild boar Sus scrofa L. in central Europe. Euro J Wildl Res 59:805-814

Krijger IM, Belmain SR, Singleton GR, Koerkamp P, Meerburg BG (2017) The need to implement the landscape of fear within rodent pest management strategies. Pest Manag Sci 73:2397-2402

Lapidge SJ, Wishart J, Staples L, Fagerstone K, Campbell TA, Eiseman J (2012) Development of a Feral Swine Toxic Bait $\left(\right.$ Hog-Gone $\left.{ }^{\circledR}\right)$ and Bait Hopper (Hog-Hopper ${ }^{\mathrm{TM}}$ ) in Australia and the USA. In: Frey SN (ed) Proceedings of the 14th WDM conference, pp 19-24

Lavelle MJ, Snow NP, Halseth JM, Kinsey JC, Foster JA, VerCauteren KC (2018a) Development and evaluation of a bait station for selectively dispensing bait to invasive wild pigs. Wildl Soc Bull 42:102-110

Lavelle MJ, Snow NP, Halseth JM, VanNatta EH, Sanders HN, VerCauteren KC (2018b) Evaluation of movement behaviors to inform toxic baiting strategies for invasive wild pigs (Sus scrofa). Pest Manag Sci 74:2504-2510

Lemel J, Truve J, Soderberg B (2002) Variation in ranging and activity behavior of European wild boar Sus scrofa in Sweden. Wildl Biol 9(Suppl 1):29-36

Massei G, Genov PV (2004) The environmental impact of wild boar. Galemys 16:135-145

Mayer JJ (2009) Wild pig population biology. In: Mayer J, Brisbin Jr. IL (eds) Wild pigs biology, damage, control, techniques, and management. Savannah River National Laboratory, Aiken, SC, USA, pp 157-191

Mayer J, Brisbin IL (eds) (2009) Wild pigs: biology, damage, control techniques and management, vol SRNL-RP-2009-00869. Savannah River National Laboratory, Aiken, South Carolina, USA

McCann BE, Garcelon DK (2008) Eradication of feral pigs from Pinnacles National Monument. J Wildl Manage 72:1287-1295

McMahon CR, Brook BW, Collier N, Bradshaw CJA (2010) Spatially explicit spreadsheet modelling for optimising the efficiency of reducing invasive animal density. Methods Ecol Evol 1:53-68

Mellish JM, Sumrall A, Campbell TA, Collier BA, Neill WH, Higginbotham B, Lopez RR (2014) Simulating potential population growth of wild pig, Sus scrofa, in Texas. Southeast Nat 13:367-376

Morrison SA, Macdonald N, Walker K, Lozier L, Shaw MR (2007) Facing the dilemma at eradication's end: uncertainty of absence and the Lazarus effect. Front Ecol Env 5:271-276

Muir TJ, McEwen G (2007) Methods and strategies for managing feral hog damage in grain production areas in central Texas. In: Witmer GW, WCP, Fagerstone KA (ed) Managing vertebrate invasive species: proceedings of an international symposium. USDA/APHIS/ WS, National Wildlife Research Center, Fort Colling, CO

Parkes JP, Ramsey DSL, Macdonald N, Walker K, McKnight S, Cohen BS, Morrison SA (2010) Rapid eradication of feral pigs (Sus scrofa) from Santa Cruz Island, California. Biol Conserv 143:634-641

Patergnani M, Gras LM, Poglayen G, Gelli A, Pasqualucci F, Farina M, Stancampiano L (2010) Environmental influence on urban rodent bait consumption. J Pest Sci 83:347-359

Pelz HJ et al (2005) The genetic basis of resistance to anticoagulants in rodents. Genetics 170:1839-1847

Pepin KM, Davis AJ, Cunningham FL, VerCauteren KC, Eckery DC (2017a) Potential effects of incorporating fertility control into typical culling regimes in wild pig populations. PLoS ONE 12:e0183441
Pepin KM, Davis AJ, VerCauteren KC (2017b) Efficiency of different spatial and temporal strategies for reducing vertebrate pest populations. Ecol Model 365:106-118

Pimentel D (2007) Environmental and economic costs of vertebrate species invasions into the United States. In: Witmer GW, Pitt WC, Fagerston KA (eds) Managing vertebrate invasive species: proceedings of an international symposium. U.S. Department of Agriculture, Animal and Plant Health Inspection Service, Wildlife Services, National Wildlife Research Center, pp 2-8

Pimentel D, Lach L, Zuniga R, Morrison D (2000) Environmental and economic costs of nonindigenous species in the United States. Bioscience 50:53-65

Podgorski T, Lusseau D, Scandura M, Sonnichsen L, Jedrzejewska B (2014) Long-lasting, kin-directed female interactions in a spatially structured wild boar social network. PLoS ONE 9:e99875

Prevot C, Licoppe A (2013) Comparing red deer (Cervus elaphus L.) and wild boar (Sus scrofa L.) dispersal patterns in southern Belgium. Euro J Wildl Res 59:1-9

Queensland TS (2008) Feral pig control: a practical guide to pig control in Queensland. https://www.daf.qld.gov.au/_data/assets/pdf_ file/0008/63926/IPA-Feral-Pig-Control-Manual.pdf. Last accessed 20 Dec 2019

Raynor EJ, Beyer HL, Briggs JM, Joern A (2017) Complex variation in habitat selection strategies among individuals driven by extrinsic factors. Ecol Evol 7:1802-1822

Savarie PJ, Shivik JA, White GC, Hurley JC, Clark L (2001) Use of acetaminophen for large-scale control of brown treesnakes. J Wildl Manage 65:356-365

Schley L, Dufrêne M, Krier A, Frantz AC (2008) Patterns of crop damage by wild boar (Sus scrofa) in Luxembourg over a 10-year period. Euro J Wildl Res 54:589-599

Shapiro L, Eason C, Bunt C, Hix S, Aylett P, MacMorran D (2016) Efficacy of encapsulated sodium nitrite as a new tool for feral pig management. J Pest Sci 89:489-495

Snow NP, Foster JA, Kinsey JC, Humphrys ST, Staples LD, Hewitt DG, VerCauteren KC (2017a) Development of toxic bait to control invasive wild pigs and reduce damage. Wildl Soc Bull 41:256-263

Snow NP, Lavelle MJ, Halseth JM, Blass CR, Foster JA, Vercauteren KC (2017b) Strength testing of raccoons and invasive wild pigs for a species-specific bait station. Wildl Soc Bull 41:264-270

Snow NP, Foster JA, VanNatta EH, Horak KE, Humphrys ST, Staples LD, Hewitt DG, VerCauteren KC (2017c) Potential secondary poisoning risks to non-targets from a sodium nitrite toxic bait for invasive wild pigs. Pest Manag Sci 74:181-188

Snow NP et al (2018) Exposure of a population of invasive wild pigs to simulated toxic bait containing biomarker: implications for population reduction. Pest Manag Sci 75:1140-1149

Snow NP, Horak KE, Humphrys ST, Staples LD, Hewitt DG, VerCauteren KC (2019) Low secondary risks for coyotes from sodium nitrite toxic bait for invasive wild pigs. Wildl Soc Bull 43:484-490

Steen D (2006) The benefits of aerial hunting for feral hog management in Southeast Texas pasture and rangelands. In: Proceedings of the 22nd vetebrate pest conference, pp 361-363

Timmons JB et al. (2012) Feral hog population growth, density and harvest in Texas. http://feralhogs.tamu.edu/files/2010/04/FeralHogPo pulationGrwothDensityandHervestinTexasedited.pdf. Texas A \& M, Last accessed 20 Dec 2019

Tompkins DM, Ramsey D (2007) Optimising bait-station delivery of fertility control agents to brushtail possum populations. Wildl Res 34:67-76

Twigg LE, Martin GR, Lowe TJ (2002) Evidence of pesticide resistance in medium-sized mammalian pests: a case study with 1080 poison and Australian rabbits. J Appl Ecol 39:549-560

Wilber MQ, Chinn SM, Beasley JC, Boughton RK, Brook RK, Ditchkoff SS, Fischer JW, Hartley SB, Holmstrom LK, Kilgo JC, Lewis JS, Miller RS, Snow NP, VerCauteren KC, Wisely SM, Webb CT, Pepin 
KM (2020) Predicting functional responses in agro-ecosystems from animal movement data to improve management of invasive pests. Ecol Appl 2019:e02015

Yokomizo H, Possingham HP, Thomas MB, Buckley YM (2009) Managing the impact of invasive species: the value of knowing the densityimpact curve. Ecol Appl 19:376-386
Publisher's Note Springer Nature remains neutral with regard to jurisdictional claims in published maps and institutional affiliations. 


\title{
Supplementary Information for:
}

\section{Optimal bait density for delivery of acute toxicants to vertebrate pests}

\author{
Kim M. Pepin, Nathan P. Snow, Kurt C. VerCauteren
}

\section{Individual-based model}

Below we describe the spatially-explicit individual-based model using the ODD Protocol (Grimm et al. 2010). A schematic of the model components is given in Fig.S1.

\section{Purpose}

The purpose of the model is:

- To predict cost-effectiveness of using different densities of bait sites for reduction of a wild pig population by a target proportion.

- To understand how strength of avoidance behavior in previously exposed individuals affects cost-effectiveness of the baiting strategy.

II. Entities, state variables, and scales

II.1 Wild pigs

Individual wild pigs and bait sites were the entities in the model. Attributes for individual wild pigs included: age, sex, social group, age at dispersal, longevity, home range radius, movement 
distance, home range centroid, bait exposure status, and carrying capacity of their home grid cell. For females, we additionally tracked reproductive status, gestation time, and time since the last birthing event. Wild pig states were either alive and not yet exposed to toxic bait or alive and recovered from toxic bait exposure. Wild pigs that died from toxic bait exposure were permanently removed from the population.

\section{II.2 Bait sites}

Bait sites had three states: 1) 'locating' (where non-toxic pre-bait (e.g., corn) is placed on the ground to locate wild pigs, no bait site is present), 2) 'training' (where wild pigs have been located and a bait site has been placed and baited with non-toxic pre-bait). During this phase wild pigs become accustomed to using the bait site. Finally, state 3 ) is the 'toxic' phase (1 night of toxic baiting followed by 2 nights of non-toxic baiting for up to 3 cycles or until no wild pigs returned). For each bait site we tracked: the state, the number of pigs that visited per day, and the location of the bait site on the habitat grid in continuous space.

\section{II.3 Space}

Wild pig daily movements occurred in continuous space but the habitat grid that defined heterogeneity in abundance consisted of 225 discrete $4 \mathrm{~km}^{2}$ cells (total area $900 \mathrm{~km}^{2}$ ). We examined landscapes with densities of $1,3,5$, or 10 wild pigs / $\mathrm{km}^{2}$ (i.e., abundance at biological carrying capacity of $900,2700,4500$, or 9000 wild pigs), which encompasses the high and low range of wild pig densities in high-density regions of southern USA (Davis et al. 2017; Keiter et al. 2017). For this analysis we assumed a homogenous distribution of density (i.e., without variation in density due to landscape factors) in order to isolate the effects of animal density from 
heterogeneity in density. We also assumed that interactions with conspecifics did not affect visitation rates to bait sites.

\section{Process overview and scheduling}

After a 31 year burn-in period of the population dynamics (Fig. S2), the following events occurred in the model on a daily time step (processes described below in 'Submodels'):

a. Bait site dynamics, which included visits of wild pigs to each bait site, effects of the toxic bait on individual wild pigs, updates of the bait site status, updates of effort and costs, and relocation of bait sites as needed.

b. Natal dispersal, where wild pigs that reached their age of dispersal relocated to a new home range centroid.

c. Social structure, where independent females joined nearby family groups and oversized groups were divided in half with one group moving to a new home range centroid.

d. Density-dependent immigration, where new wild pigs from an exogenous population migrated to the landscape.

e. Conception, births, and natural mortality, where reproductively active females in grid cells below carrying capacity were allowed to conceive and then birth a litter following a gestation period. Wild pigs at the age of longevity in natural populations were removed from the population.

Each simulation was run for a total of 5 years. 


\section{Design concepts}

\section{IV.1 Basic principles}

We used an individual-level model of wild-pig population dynamics to account for variation in bait-site status due to variation in wild pig visitation and consumption rates. We also accounted for changes in management costs as a function of population density and spatial extent of baiting. We examined the effects of management objectives, initial population density, toxic bait efficacy, and post-exposure avoidance on cost-effectiveness of bait-density designs.

\section{IV.2 Emergence and adaptation}

Both immigration and birth rates were density-dependent such that their rates changed as a function of population density under the assumption that individuals could adapt to density. Also, effort per wild pig increased with decreasing population density because bait sites were maintained until the last wild pig in a grid cell was removed. That is, at lower densities, fewer wild pigs were removed per day of toxic bait application. These non-linearities caused complex behavior in the total costs required to reach the management objective.

\section{IV.3 Learning}

Individuals that consumed toxic bait and recovered were able to avoid toxic bait in the future. This learning also affected their offspring that were currently in their family group, in that they too avoided baits. 


\section{IV.4 Sensing}

The managers were able to detect wild pig presence (whether or not there were still wild pigs in a given grid cell) - when bait sites were moved, they were relocated to grid cells that had at least one wild pig. Also, the number of bait sites decreased as wild pigs were eliminated from regions of the landscape, because managers were able to sense the decrease in wild pig density. In addition, individual wild pigs sensed grid cell abundance in grid cells they were dispersing to and did not disperse to grid cells that were at or above carrying capacity. Groups also sensed when there were too many members and spilt up when they grew above a maximum capacity (Table S1). Independent females sensed when they were alone and dispersed to join the nearest group.

\section{IV.5 Stochasticity}

Most parameter inputs were random distributions (Table S1). Also, movements on the landscape were random except for sensing density.

\section{IV.6 Observation}

We tracked daily abundance of wild pigs by sex and age group, area covered by wild pigs, cumulative monetary cost of the strategy, and cumulative effort (in terms of bait site days). We also tracked average sounder size and the ratio of annual births to removals by toxicant in order to understand the demographic effects of toxicant application. We determined the optimal strategy as the one that cost the lowest to reach a particular population reduction objective ('management target'). 


\section{Initialization}

An empty matrix of individuals was initialized with the number of rows equivalent to the desired population size. Each individual (row) was assigned attributes at random (Table S1). Current age and longevity were chosen from a gamma distribution such that the current age was less than the longevity. Sex was assigned at random using a 50:50 ration of males:females. Dispersal age was assigned from a Poisson distribution (Table S1) - males whose age was beyond dispersal age, dispersal status was recorded as completed. Males beyond the age of dispersal were not assigned to a family group. All other individuals were assigned a unique group ID at random. The 30 year burn-in period allowed for group structure to develop and stabilize. Each individual was assigned to a grid cell ID and specific [x,y] coordinates within that grid cell, both of which were selected at random. After the population was initialized, population dynamics were allowed to occur for 30 years (Fig. S2). The population at the end of the 30 years, which was at carrying capacity, served as the starting point for all simulations with the bait site dynamics. To allow for stochasticity from the initial population structure, we generated 100 different starting populations and selected from that set at random when initializing the bait site simulations.

\section{Input data}

Input data are described in Table S1.

\section{Submodels}

VII.1 Bait-site dynamics 
For each simulation, bait sites were initialized on day 90 using the pre-determined baitdensity design ('treatment') and the current abundance (i.e., the total abundance at day 90 divided by the parameter defining the number of bait sites per wild pig). We specified that 1.2 bait sites were initialized for every available bait sites, so that only the best $83 \%$ of bait sites with the most visitation by wild pigs progressed to the next state of placing a bait site. All bait sites were placed randomly across a homogenous landscape. The status of each bait site was tracked as: active baiting with no bait site, training pigs to use bait site, containing toxic bait, containing non-toxic bait (posttoxic baiting) for evaluation of further visitation.

Decisions to transition between these states were informed by visitation data and predefined time limits based on previous research (Lavelle et al. 2018) (Fig. S1). After a bait site was initialized, it was pre-baited for 5 days to determine if there were wild pigs visiting. Bait sites with no visits were discontinued. If there were not enough 'good' bait sites (i.e., bait sites with wild pigs that visited) for the number of available bait sites, then new bait sites were established (as above) at 1.2 times the number of available bait sites. Bait sites with the highest number of unique wild pigs visiting were prioritized for setting up the available bait sites (as defined by the bait site density treatment). Bait sites were then baited for 14 days (training time) to allow time for wild pigs to learn how to use the bait site. At the end of 14 days, toxic bait was added for 1 day. Wild pigs that visited and ate the toxic bait (process described below) had a fixed probability of dying of 0.95 (Snow et al. 2017). The next day, placebo bait was added for an additional two days to monitor for additional visits. If, after the two days of placebo bait, there were additional visits, then toxic bait was added for an additional day. This cycle between toxic baiting and evaluation with placebo bait occurred up to 3 times. If there were no visits after any of the earlier toxic bait sessions, the bait site was removed and made available to be set-up in a new location. 


\section{VII.2 Bait site relocation.}

We assumed that wild pig presence in grid cells was known through wild pig sign. Thus, bait sites were only placed in grid cells with at least one wild pig. Within this constraint, the spatial relocation occurred at random by first choosing a random grid cell with at least one wild pig and then choosing a random $\mathrm{x}$ and $\mathrm{y}$ coordinate within that grid cell. If there were already the target number of bait sites (based on the treatment), then bait sites that were ready to be moved were removed but not reset in new locations. We calculated the available bait sites each day based on the current wild pig abundance and treatment density, the number of bait sites that were active, and the number that were available to be placed in new locations (i.e., number of available bait sites $=$ abundance/treatment - number of active bait sites; where the minimum is 0 ). Available bait sites were assigned to new bait sites that were determined to have wild pig visitation (as described above) and new bait sites were initiated at a frequency that maintained 1.2 bait sites per available bait site (as described above).

\section{VII.3 Wild pig visitation to bait sites.}

Overall, our visitation algorithm accounted for sex, age, and distance-based determination of bait consumption, non-independence of wild pig-bait site associations due to social structure, and potential avoidance behavior from previous exposure to toxic bait. For each wild pig each day, we calculated the probability that a wild pig would visit and eat from each bait site using a generalized mixed logistic model and data from (Snow et al. 2018) (Table S1). Briefly, the response was binary whether or not a wild pig consumed bait. The covariates predicting the probability of bait consumption were: sex, age class (piglet: 0-0.5 years, juvenile: 0.5-1.5 years, adult: 1.5 years + ), and distance between pig home range centroids and the nearest bait site (data and model fit in Table S1). The model also included a grouping variable for family groups to account for non- 
independence due to social structure. The fitted model was used to predict the probability of consumption at each day (per wild pig, per bait site) using current data in the simulations (wild pig sex, wild pig age class, distance between the wild pig's home range centroid and the bait site coordinates, family group ID). Next, for bait site locations that were farther than the wild pig individual's home range radius (Table S1), we set the visitation probability to 0 . For all individuals that had previously encountered toxic bait and recovered, we multiplied their visitation probability (as well as their offspring that were currently in the same family group) to bait sites by an avoidance parameter (Table S1). We then chose a uniform random number for each wild pig x bait site combination as a critical value. Critical values less than the overall visitation probability were recorded as visitations, while all other cases did not result in visitation at this time step. Lastly, because wild pigs rarely visit more than 3 different bait sites (Snow et al. 2018), we only allowed up to three different bait sites to be visited per wild pig per day, and these were chosen at random from the bait sites per wild pig that were recorded as visits (as above).

The process for consumption of toxic bait was the same except that wild pigs that consumed toxic bait died with a fixed probability (Table S1; again, using a randomly chosen critical value per wild pig and bait site). We also implemented a maximum feeding capacity per bait site location per day (Table S1). For bait sites that had more than the maximum number of wild pigs feeding on one day, we randomly selected a number of individual wild pigs equal to the excess number and did not allow them access that day.

\section{VII.4 Tracking costs.}

Costs were tracked in 4 categories: 1 ) initial costs for equipment (based on the maximum number of bait sites employed simultaneously and the cost per bait site), 2) salary and supplies costs for setting up or removing bait sites, 3) daily salary and supplies costs for running non-toxic 
pre-baiting and post-baiting, and 4) daily salary and supplies costs for running bait sites with toxic bait. For each of these categories we assumed that costs increased linearly with the number of bait sites and average distance between them. Costs for the bait sites were only accrued once, despite their re-use. Costs of non-toxic and toxic baits were factored into every category. For each category, the per day costs $\left(c_{t}\right)$ were calculated as: $c_{t}=b_{1}+m \cdot b_{1} \cdot N_{b, t} \cdot d_{b, t}$, where $b_{1}$ is the labor and supplies cost for baiting one site, $N_{b, t}$ is the total number of bait sites at time $t, d_{b, t}$ is the average pairwise distance between all bait sites at time $t$, and $m$ is the slope of the relationship between cost and the bait site number $x$ spatial area metric. For example, if the cost of running one bait site for a day with placebo bait is $\$ 10$, and $m=0.5$, the cost to run 5 bait sites with placebo bait per day spaced at 1 $\mathrm{km}^{2}$ on average would be: $\$ 10+\left(0.5 \cdot \$ 10 \cdot 5\right.$ bait sites $\left.\cdot 1 \mathrm{~km}^{2}\right)=\$ 35$. The total cost at each time step was the sum of all 4 categories, and the total cost for the whole run was the sum across time and categories. We chose the following fixed parameters in each category (shown as $\left[b_{1}, m\right]$ ): 1 ) $\$ 100$ (equipment costs per bait site - no $m$ parameter), 2) [\$15, 0.05], 3) [\$10, 0.05], and 4) [\$50, 0.05]. We assumed that an adequate number of cameras were available to have one camera per bait site, thus camera/battery costs were not included in our overall costs.

\section{VII.5 Natal dispersal}

Wild pigs were assigned an age of natal dispersal at birth (Table S1). At the age of dispersal, males dispersed independently to a new unique location, while females dispersed with their sisters. Dispersal distance was chosen from a Weibull distribution (Table S1). The dispersal algorithm operated as follows: 1) for each 45 degree angle from the home range centroid, a new possible set of $[\mathrm{x}, \mathrm{y}]$ coordinates was obtained using the dispersal distance value (i.e. $\mathrm{x}=$ distance $\mathrm{x} \cos ($ angle $)+$ current $\mathrm{x}$ coordinate, $\mathrm{y}=$ distance $\mathrm{x} \sin ($ angle $)+$ current $\mathrm{y}$ coordinate $)$. If at least one of these potential locations were valid (i.e., in a grid cell with fewer wild pigs than the carrying capacity or a location off the grid), 
then a valid potential location was chosen at random and wild pig(s) were relocated there. Wild pigs that traveled off the grid were lost permanently. If there were no valid locations, the distance value was doubled and the process repeated until a valid location was obtained.

\section{VII.6 Social structure}

All newborns were assigned the same group ID as their mothers and remained in those groups until natal dispersal. To maintain realistic group sizes we also implemented a maximum family group size (Table S1). For family groups at maximum capacity, the group was split in half, selecting one mature female and a subgroup of younger individuals to disperse together. Also, because adult females are rarely observed alone (Gabor et al. 1999; Podgorski et al. 2014), any adult females that were found independent of a group on the landscape dispersed to join the nearest family group. These relocations to maintain social structure occurred the same way as natal dispersal.

\section{VII.7 Density-dependent immigration}

Immigration from an exogenous population was allowed to occur in the periphery grid cells of the landscape. At each time step, the grid cells that were below carrying capacity were used to calculate the immigration rate as described in Table S1. To examine the effects of the strength of immigration on effectiveness, we varied $\mu$, the scaling parameter (Table S1). The number of new immigrants were distributed at random with replacement in the set of grid cells below carrying capacity. Other attributes for these immigrants were initialized as described in the initialization section. 


\section{VII.8 Conception, births, and natural mortality}

Conceptions occurred randomly in reproductively active females (Table S1) according to a daily conception probability which varied monthly (Table S1). Pregnant females gave birth to a random number of offspring (Table S1) with a 50:50 ratio of males:females, after a gestation period of 115 days (Table S1). After birthing, there was a fixed lag before the possibility of conceiving again to allow for a period of lactational anestrus (Table S1). Thus, the maximum number of litters per year was 2 . Net population growth rate was controlled by multiplying the daily conception probability by a scaling parameter (Table S1). We chose the scaling parameter so as to yield net population growth rates of 1.4 for population densities at 10\% for carrying capacity (Fig. S2), consistent with (Bieber and Ruf 2005; Mellish et al. 2014; Timmons et al. 2012). Additionally, conception probability was density dependent such that conception did not occur in individuals existing in grid cells that were already beyond carrying capacity. Thus, the general host demographic dynamics were similar to a logistic model (see Pepin et al. 2017) for direct comparison). We modeled natural mortality by assigning each individual a longevity at birth that was a gamma-distributed random number such that the probability of living longer was smaller than the probability of dying young (Table S1).

Model assumptions

We assumed that birth rates were density-dependent such that their rates changed as a function of population density under the assumption that individuals could adapt to density. We assumed individual wild pigs did not disperse to grid cells that were at or above carrying capacity. Also, effort per wild pig increased with decreasing population density because bait sites were maintained until the last wild pig in a grid cell was removed. That is, at lower densities, fewer wild pigs were 
removed per day of toxic bait application. These non-linearities caused complex behavior in the total costs required to reach the management objective. In terms of bait visitation and consumption, we assumed that the only factors determining these rates included age, sex, group membership, and distance to the baits. When examining post-exposure avoidance behavior, we assumed that a proportion of individuals that consumed toxic bait and recovered would avoid toxic bait in the future (i.e., based on 1-bait efficacy). This learning was also communicated to others in the family group, but not after the offspring had dispersed from the family group. We also assumed that managers were able to detect wild pig presence (whether or not there were still wild pigs in a given grid cell) - when bait sites were initialized or moved, they were set-up in grid cells that had at least one wild pig. The number of bait sites decreased as wild pigs were eliminated from regions of the landscape, because we assumed managers used trail cameras and wild pig sign to detect a lack of visitation to bait sites.

Table S1. Description of parameters.

\begin{tabular}{|c|c|c|}
\hline Parameter & Values & References \\
\hline \multicolumn{3}{|c|}{ Demographic parameters } \\
\hline Longevity & $\sim \operatorname{gamma}(0.95,738)$, truncated at 11 years. & (Jezierski 1977) \\
\hline $\begin{array}{l}\text { Daily conception probability } \\
\text { per individual } \\
\text { (fecundity) }\end{array}$ & $\begin{array}{l}\text { Daily probability of conceiving = monthly data of } \\
\text { proportion that conceive }([0.210 .170 .0720 .0750 .11 \\
0.0590 .0490 .0490 .0130 .0490 .0260 .12]) / \text { days per } \\
\text { calendar month (i.e., the probability of conception per } \\
\text { day in a calendar month). These values were then } \\
\text { multiplied by a scaling factor }(3,1.1 \text {, or } 1.1 \text { in } \\
\left.\text { population densities of } 4,20 \text {, or } 40 \text { wild pigs per } \mathrm{km}^{2}\right) \text { to } \\
\text { generate population dynamics similar to observed data } \\
(\lambda=1.4 \text { at abundances well below carrying capacity). } \\
\text { See Fig. S1 and Pepin et al. (2017) for example } \\
\text { population dynamics. }\end{array}$ & $\begin{array}{l}\text { (Mayer and Brisbin } \\
\text { 2009)(Fig. } 1 \text { pg 67); } \\
\text { (Timmons et al. } \\
\text { 2012) } \\
\text { (Mellish et al. 2014) }\end{array}$ \\
\hline Litter size & $\sim$ Poiss(5 piglets), truncated at 1 and 12 & $\begin{array}{l}\text { (Bieber and Ruf } \\
\text { 2005; Gethoeffer et } \\
\text { al. 2007) }\end{array}$ \\
\hline $\begin{array}{l}\text { Age at reproductive maturity } \\
\text { (minimum age at which females } \\
\text { may conceive) }\end{array}$ & 180 days & $\begin{array}{l}\text { (Gethoeffer et al. } \\
\text { 2007) }\end{array}$ \\
\hline
\end{tabular}




\begin{tabular}{|c|c|c|}
\hline $\begin{array}{l}\text { Minimum time between } \\
\text { farrowing and conception }\end{array}$ & 90 days & (Barrett 1978) \\
\hline Gestation time & 115 days & (Henry 1968) \\
\hline Age of natal dispersal & Poisson(456 days); truncated 304-730 days & $\begin{array}{l}\text { (Podgorski et al. } \\
\text { 2014) }\end{array}$ \\
\hline Dispersal distance & $\sim$ Weibull $(2.5,0.5)$ & $\begin{array}{l}\text { (Keuling et al. } \\
\text { 2010; Podgorski et } \\
\text { al. 2014; Prevot and } \\
\text { Licoppe 2013) }\end{array}$ \\
\hline Maximum group size & 15 & (Gabor et al. 1999) \\
\hline Home range radius & $\begin{array}{l}\text { Selected at random from sex-specific distributions of } \\
\text { home range size, where } \\
\qquad r=\sqrt{\frac{x}{\pi}} \\
r \text { is the home range radius, and } x \text { is the home range area } \\
\text { for an individual calculated using 95\% MCP. All } \\
\text { estimates were based on }>3 \text { months of GPS monitoring } \\
\text { data. }\end{array}$ & (Kay et al. 2017) \\
\hline \multicolumn{3}{|c|}{ Bait site parameters } \\
\hline $\begin{array}{l}\text { Bait site density (number of } \\
\text { wild pigs / bait site at } \\
\text { initiation) }\end{array}$ & $\begin{array}{l}15 \text { (baseline) } \\
2-130 \text { (sensitivity) }\end{array}$ & User-defined \\
\hline $\begin{array}{l}\text { Probability of visitation } \boldsymbol{\&} \\
\text { consumption } \\
\text { (daily probabilities) }\end{array}$ & $\begin{array}{l}Y \sim \operatorname{Binomial}(N, p) \\
\text { Logit }(p)=\boldsymbol{\beta} \mathbf{X}+\rho, \text { where } \mathbf{X}=\text { sex, age class, and } \\
\text { distance to the nearest bait site. } \\
\text { (see Table } \mathrm{S} 3 \text { for data and fitted model). }\end{array}$ & (Snow et al. 2018) \\
\hline $\begin{array}{l}\text { Probability of dying given } \\
\text { consumption }\end{array}$ & $\begin{array}{l}0.93 \text { (baseline) } \\
0.51-0.99 \text { (sensitivity) }\end{array}$ & (Snow et al. 2017) \\
\hline Avoidance & $\begin{array}{l}0 \text { (baseline, i.e., no avoidance) } \\
0-1 \text { (sensitivity) }\end{array}$ & Unknown \\
\hline
\end{tabular}




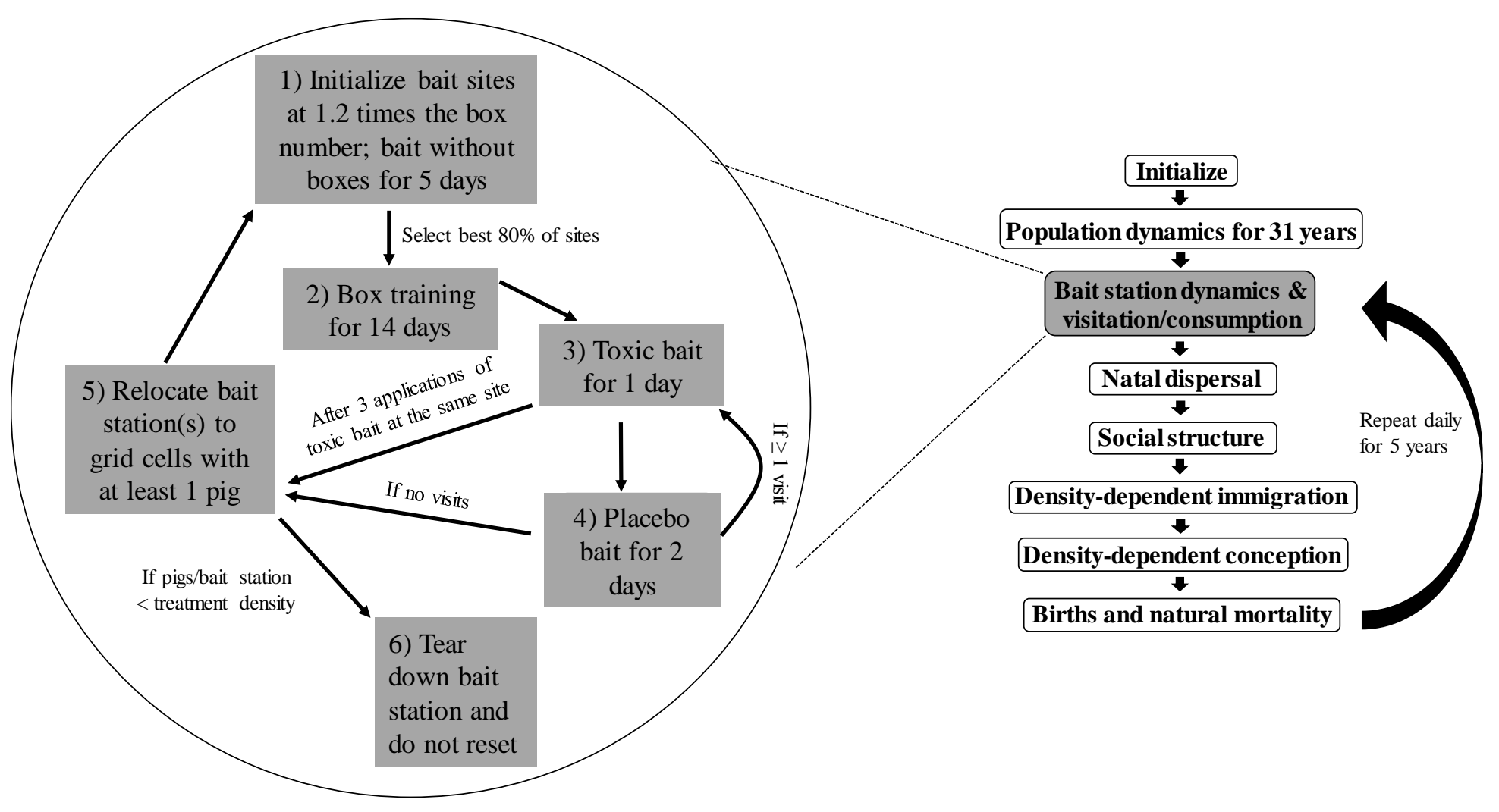

Fig. S1. Schematic of the model processes. 

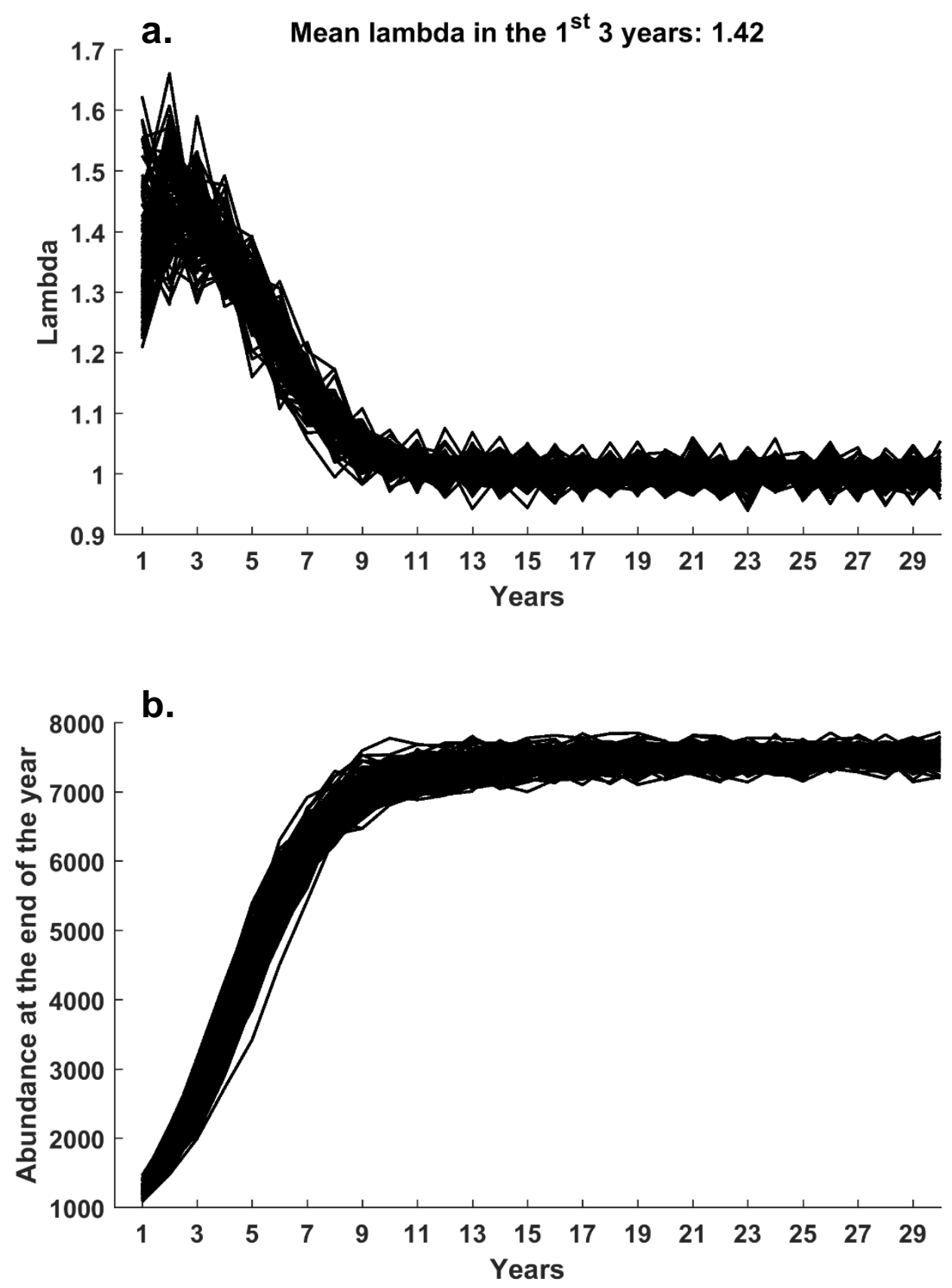

Fig. S2. Population dynamics during the burn-in period (30 years of population dynamics with no baiting are shown). Each line represents the annual population growth rate (lambda; a) or abundance trajectory (b) for one stochastic simulation (100 total were conducted). End point populations served as the initial conditions for the runs with baiting. 


\section{References}

Barrett RH (1978) The feral hog on the Dye Creek Ranch, California. Hilgardia 46:283-355

Bieber C, Ruf T (2005) Population dynamics in wild boar Sus scrofa: ecology, elasticity of growth rate and implications for the management of pulsed resource consumers. J Appl Ecol 42:1203-1213

Davis AJ, Leland B, Bodenchuk M, VerCauteren KC, Pepin KM (2017) Estimating population density for disease risk assessment: The importance of understanding the area of influence of traps using wild pigs as an example. Prev Vet Med 141:33-37

Gabor TM, Hellgren EC, Van Den Bussche RA, Silvy NJ (1999) Demography, sociospatial behaviour and genetics of feral pigs (Sus scrofa) in a semi-arid environment $\mathbf{J}$ Zool, London 247:311-322

Gethoeffer F, Sodeikat G, Pohlmeyer K (2007) Reproductive parameters of wild boar (Sus scrofa) in three different parts of Germany. Euro J Wildl Res 53:287-297

Grimm V, Berger U, DeAngelis DL, Polhill JG, Giske J, Railsback SF (2010) The ODD protocol A review and first update. Ecol Model 221:2760-2768

Henry VG (1968) Length of estrous cycle and gestation in European wild hogs. J Wildl Manage $32: 406-408$

Jezierski W (1977) Longevity and mortality rate in a population of wild boar. Acta Theriol $22: 337-348$

Kay SL et al. (2017) Quantifying drivers of wild pig movement across multiple spatial and temporal scales. Mov Ecol 5:14

Keiter DA, Davis AJ, Rhodes OE, Cunningham FL, Kilgo JC, Pepin KM, Beasley JC (2017) Effects of scale of movement, detection probability, and true population density on common methods of estimating population density. Sci Rep 7:9446

Keuling O, Lauterbach K, Stier N, Roth M (2010) Hunter feedback of individually marker wild 
boar Sus scrofa L.: dispersal and efficiency of hunting in northeastern Germany. Euro J Wildl Res 56:159-167

Lavelle MJ, Snow NP, Halseth JM, VanNatta EH, Sanders HN, VerCauteren KC (2018) Evaluation of movement behaviors to inform toxic baiting strategies for invasive wild pigs (Sus scrofa). Pest Manag Sci 74:2504-2510

Mayer J, Brisbin IL (eds) (2009) Wild pigs: biology, damage, control techniques and management. vol SRNL-RP-2009-00869. Savannah River National Laboratory, Aiken, South Carolina, USA

Mellish JM, Sumrall A, Campbell TA, Collier BA, Neill WH, Higginbotham B, Lopez RR (2014) Simulating Potential Population Growth of Wild Pig, Sus scrofa, in Texas. Southeast Nat 13:367-376

Pepin KM, Davis AJ, Cunningham FL, VerCauteren KC, Eckery DC (2017) Potential effects of incorporating fertility control into typical culling regimes in wild pig populations. PLoS One 12:e0183441

Podgorski T, Lusseau D, Scandura M, Sonnichsen L, Jedrzejewska B (2014) Long-lasting, kindirected female interactions in a spatially structured wild boar social network. PLoS One 9:e99875

Prevot C, Licoppe A (2013) Comparing red deer (Cervus elaphus L.) and wild boar (Sus scrofa L.) dispersal patterns in southern Belgium. Euro J Wildl Res 59:1-9

Snow NP, Foster JA, Kinsey JC, Humphrys ST, Staples LD, Hewitt DG, VerCauteren KC (2017) Development of toxic bait to control invasive wild pigs and reduce damage Wildl Soc Bull 41:256-263

Snow NP et al. (2018) Exposure of a population of invasive wild pigs to simulated toxic bait containing biomarker: implications for population reduction. Pest Manag Sci 75:11401149

Timmons JB et al. (2012) Feral hog population growth, density and harvest in Texas. http://feralhogs.tamu.edu/files/2010/04/FeralHogPopulationGrwothDensityandHervestin 
Texasedited.pdf, Texas A \& M; last accessed Dec. 20 2019. 